\title{
An empirically derived inorganic sea spray source function incorporating sea surface temperature
}

\author{
M. E. Salter ${ }^{1}$, P. Zieger ${ }^{1}$, J. C. Acosta Navarro ${ }^{1}$, H. Grythe ${ }^{1,2,3}$, A. Kirkevåg ${ }^{4}$, B. Rosati ${ }^{5}$, I. Riipinen ${ }^{1}$, and \\ E. D. Nilsson ${ }^{1}$ \\ ${ }^{1}$ Stockholm University, Department of Environmental Science and Analytical Chemistry, 11418 Stockholm, Sweden \\ ${ }^{2}$ Norwegian Institute for Air Research, P.O. Box 100, 2027 Kjeller, Norway \\ ${ }^{3}$ Finnish Meteorological Institute, Air Quality Research, Erik Palmenin aukio 1, P.O. Box 503, 00101 Helsinki, Finland \\ ${ }^{4}$ Norwegian Meteorological Institute, P.O. Box 43, Blindern, 0313 Oslo, Norway \\ ${ }^{5}$ Paul Scherrer Institute, Laboratory of Atmospheric Chemistry, 5232 Villigen, Switzerland
}

Correspondence to: M. E. Salter (matthew.salter@aces.su.se)

Received: 20 April 2015 - Published in Atmos. Chem. Phys. Discuss.: 13 May 2015

Revised: 4 September 2015 - Accepted: 15 September 2015 - Published: 6 October 2015

\begin{abstract}
We have developed an inorganic sea spray source function that is based upon state-of-the-art measurements of sea spray aerosol production using a temperature-controlled plunging jet sea spray aerosol chamber. The size-resolved particle production was measured between 0.01 and $10 \mu \mathrm{m}$ dry diameter. Particle production decreased non-linearly with increasing seawater temperature (between -1 and $30^{\circ} \mathrm{C}$ ) similar to previous findings. In addition, we observed that the particle effective radius, as well as the particle surface, particle volume and particle mass, increased with increasing seawater temperature due to increased production of particles with dry diameters greater than $1 \mu \mathrm{m}$. By combining these measurements with the volume of air entrained by the plunging jet we have determined the size-resolved particle flux as a function of air entrainment. Through the use of existing parameterisations of air entrainment as a function of wind speed, we were subsequently able to scale our laboratory measurements of particle production to wind speed. By scaling in this way we avoid some of the difficulties associated with defining the "white area" of the laboratory whitecap - a contentious issue when relating laboratory measurements of particle production to oceanic whitecaps using the more frequently applied whitecap method.

The here-derived inorganic sea spray source function was implemented in a Lagrangian particle dispersion model (FLEXPART - FLEXible PARTicle dispersion model). An estimated annual global flux of inorganic sea spray aerosol of $5.9 \pm 0.2 \mathrm{Pg} \mathrm{yr}^{-1}$ was derived that is close to the median of
\end{abstract}

estimates from the same model using a wide range of existing sea spray source functions. When using the source function derived here, the model also showed good skill in predicting measurements of $\mathrm{Na}^{+}$concentration at a number of field sites further underlining the validity of our source function.

In a final step, the sensitivity of a large-scale model (NorESM - the Norwegian Earth System Model) to our new source function was tested. Compared to the previously implemented parameterisation, a clear decrease of sea spray aerosol number flux and increase in aerosol residence time was observed, especially over the Southern Ocean. At the same time an increase in aerosol optical depth due to an increase in the number of particles with optically relevant sizes was found. That there were noticeable regional differences may have important implications for aerosol optical properties and number concentrations, subsequently also affecting the indirect radiative forcing by non-sea spray anthropogenic aerosols.

\section{Introduction}

Primary marine aerosol or sea spray aerosol (SSA) particles are those particles produced directly at the ocean surface following wave breaking, air entrainment as bubbles, and the subsequent bubble bursting process at the ocean surface (Lewis and Schwartz, 2004). When considered in terms of mass, sea spray aerosol particles constitute the largest 
flux of particulate matter to the atmosphere after wind-blown dust, with a global production of 3 to $30 \mathrm{Pg} \mathrm{yr}^{-1}$ (Lewis and Schwartz, 2004).

Sea spray aerosol is important for the climate system where it acts as both a direct and indirect radiative forcing component (Stocker et al., 2013). Both of these forcing effects are highly dependent upon the total number and size distribution parameters of the emitted sea spray aerosol particles; the direct effect is dominated by airborne particulate surface area, while the indirect effect is more closely related to the number of particles above a given size. Thus, sea spray aerosol properties have been the subject of significant scientific debate, centred on both the environmental factors that might affect the production of sea spray aerosol and the best experimental approach to estimate the source function of sea spray aerosol particles emitted (Lewis and Schwartz, 2004; de Leeuw et al., 2011).

Although wind speed is the major driver of air entrainment into surface waters, simply parameterising sea spray aerosol production in terms of wind speed often fails to reconcile predicted and observed sea spray aerosol concentrations (e.g. Grythe et al., 2014). Secondary factors such as wave state and sea surface temperature (SST) are known to affect a host of processes from initial air entrainment to the final production of sea spray aerosol droplets and these may in part explain these discrepancies. They may also explain some of the disparity between different sea spray aerosol source parameterisations (de Leeuw et al., 2011).

A number of recent findings have highlighted the potential importance of sea surface temperature on sea spray aerosol production. Salter et al. (2014) have shown that the interfacial bubble flux and bubble size spectra are strongly dependent on water temperature and that these are strongly correlated to total particle number flux in a laboratory setting. Grythe et al. (2014) noted a strong influence of sea surface temperature on sea spray aerosol production when they compared existing sea spray aerosol source functions with a global database of sea spray aerosol mass concentration measurements. Salisbury et al. (2014) noted large differences between a commonly used whitecap fraction parameterisation (Monahan and O'Muircheartaigh, 1980) derived almost entirely in low-latitude regions and a satellite estimate derived over the entire globe. The authors postulate that the weaker wind speed dependence observed in their global data set may in part be due to the influence of secondary factors that co-vary with the wind geographically, such as sea surface temperature. Their data indicated that at a given wind speed, the satellite-derived whitecap fraction decreases with increasing sea surface temperature (see Fig. 9 in Salisbury et al., 2013).

Much of the discussion on the role of sea surface temperature in sea spray aerosol production has focussed on the apparent contradiction between observations made using laboratory systems that attempt to replicate oceanic whitecaps and observations of sea salt concentrations made in the field or inferred from aerosol optical depth (AOD) measurements. A series of laboratory systems designed to replicate sea spray aerosol production by whitecaps have shown that the number production flux increases markedly as water temperatures are decreased (e.g. Salter et al., 2014; Zábori et al., 2013; Bowyer et al., 1990). In contrast, observational data from the field, such as chemical analysis of particulate matter smaller than $10 \mu$ min diameter $\left(\mathrm{PM}_{10}\right)$ or total suspended mass, have often been used to infer that sea spray aerosol production increases with higher sea surface temperatures due to higher observed concentrations at lower latitudes (e.g. Jaeglé et al., 2011; Grythe et al., 2014). Similarly, Sofiev et al. (2011) noted a bias between predictions of sea spray aerosol induced aerosol optical depth and measurements of aerosol optical depth when using a sea spray source function not dependent on sea surface temperature. They noted that the aerosol optical depth determined near the tropics using a sea spray aerosol source function without sea surface temperature dependence was a factor of 2 lower than observations of aerosol optical depth, suggesting that sea spray aerosol production was underestimated at lower latitudes, where sea surface temperatures are higher and wind speed is generally lower.

One explanation for the aforementioned contradiction could be the distinct properties of the sea spray aerosol that the different approaches measure. In the laboratory studies, emphasis has been placed on obtaining estimates of the number production flux of particles. The majority of these studies have focussed on particles smaller than $1 \mu \mathrm{m}$ dry diameter, both through system design and instrumental restrictions, but also because this size range dominates sea spray aerosol number production. However, particles with dry diameter larger than $1 \mu \mathrm{m}$ provide the dominant contribution to the fluxes of surface area and volume; thus, these particles are the most important for applications involving light scattering and particle mass. Consequently, studies that infer a temperature dependence of sea spray aerosol production fluxes based upon sea salt concentrations (determined from $\mathrm{PM}_{10}$ data) and aerosol optical depth measurements in the field are likely to be highly influenced by the latter properties. The incongruity between laboratory studies and aerosol optical depth/sea salt mass studies may simply result from changes to the size distribution of sea spray aerosol coincident with changes to the total number production flux as seawater temperature changes.

To test this hypothesis, we have determined the particle number flux in the size range 0.01 to $10 \mu \mathrm{m}$ dry diameter $\left(D_{\mathrm{p}}\right)$ in a temperature-controlled laboratory sea spray chamber. This set-up previously highlighted a significant dependence of particle number concentration $\left(D_{\mathrm{p}} \geq 0.01 \mu \mathrm{m}\right)$ on water temperature, with significant increases at lower water temperatures (Salter et al., 2014). However, during these experiments this system was not optimised to measure larger particles and suffered from significant particles losses for particles $D_{\mathrm{p}} \gtrsim 3 \mu \mathrm{m}$. Therefore, in order to obtain better 
comparisons with measurements of $\mathrm{PM}_{10}$, we have improved both the sampling protocol and the instrumentation used to measure particles with $D_{\mathrm{p}}$ larger than $1 \mu \mathrm{m}$ (Sect. 3). Using this new data we have derived a sea spray aerosol source function (Sect. 4) and compared it to field measurements using a Lagrangian particle dispersion model (FLEXPART; Stohl et al., 2005, see Sect. 6). Finally, we have deployed the new parameterisation in an Earth system model (NorESM; Kirkevåg et al., 2013, see Sect. 7) to facilitate comparison with its previous temperature-dependent parameterisation.

\section{Methods}

\subsection{The sea spray chamber}

In order to observe the effects of sea surface temperature on the source flux of aerosol produced, we have utilised a temperature-controlled sea spray generation chamber. This system has been described in detail by Salter et al. (2014). However, a number of modifications were made to the system to improve estimates of the aerosol particle production flux, especially for particles with $D_{\mathrm{p}}>1 \mu \mathrm{m}$.

The sea spray chamber is fabricated from stainless steel components and incorporates temperature control $\left( \pm 0.1^{\circ} \mathrm{C}\right)$ so that the water temperature can be held constant between -1 and $30^{\circ} \mathrm{C}$. Air was entrained using a plunging jet that exited a stainless steel nozzle with an inner diameter of $4.3 \mathrm{~mm}$ held in a vertical position $30 \mathrm{~cm}$ above the air-water interface. Water was circulated from the centre of the bottom of the tank back through this nozzle using a peristaltic pump (Watson-Marlow, 620S) and silicone tubing. All surfaces below the water level on the inside of the tank were coated in Teflon, and prior to all experiments all internal surfaces were rinsed thoroughly with reagent grade ethanol and low organic carbon (American Society for Testing and Materials Type 1) standard deionised water ( $>18.2 \mathrm{M} \Omega$ ), hereafter referred to as DIW.

Both seawater salinity and temperature were measured continuously using an Aanderaa 4120 conductivity sensor. Seawater dissolved oxygen concentration was measured with an Aanderaa oxygen optode 4175 . This sensor also provided an independent temperature measurement. Both sensors were placed towards the centre of the tank approximately halfway between the tank base and the air-water interface. Relative humidity and temperature were measured in the headspace of the sea spray simulator using a Vaisala model HMT333 probe.

Dry zero-sweep air entered the tank at $6 \mathrm{Lmin}^{-1}$ after passing through an ultrafilter (Type $\mathrm{H}$ cartridge, MSA) and an activated carbon filter (Ultrafilter, AG-AK). The airflow rate was maintained and quantified using a mass flow controller (Brooks, 5851S). Aerosol particle-laden air was sampled through a number of ports in the lid of the sea spray simulator and transferred under laminar flow to all aerosol in-

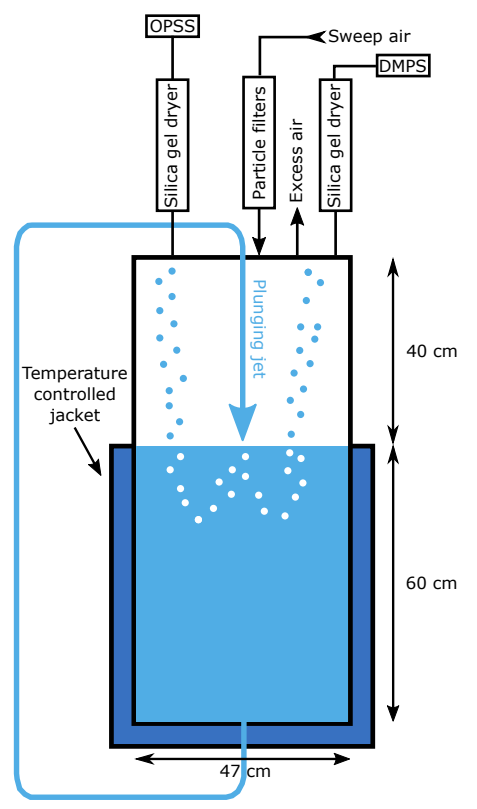

Figure 1. Schematic of the plunging jet tank used for the experiments.

strumentation. To prevent contamination by room air, the sea spray simulator was operated under slight positive pressure by maintaining the sweep air flow several $\mathrm{Lmin}^{-1}$ greater than the sampling rate. Excess air was vented through a 1way flutter valve on the lid of the system. Figure 1 is a schematic of the set-up used.

\subsection{Particle size distribution measurements}

\subsubsection{Differential mobility particle sizer and condensation particle counter}

Aerosol particle-laden air was directed through $2 \mathrm{~m}$ of $1 / 4^{\prime \prime}$ stainless steel tubing and a custom made silica diffusion dryer at which point the flow was split. Immediately following this split, a TSI model 3010 condensation particle counter (CPC) was used to enumerate the total number concentration at $1 \mathrm{~Hz}$ for particles with $D_{\mathrm{p}}>0.01 \mu \mathrm{m}$. The aerosol particle-laden air that entered the second sampling line was first directed to a custom made impactor $(0.0707 \mathrm{~cm} \mathrm{noz-}$ zle, with a cut-off diameter of $\sim 1 \mu \mathrm{m}$ at $1 \mathrm{Lmin}^{-1}$ ), it was then passed through a bipolar charger (neutraliser, Ni-63.) before it entered a closed-loop sheath air, custom-built differential mobility particle sizer (DMPS) that selected negatively charged particles using a positive high voltage in the differential mobility analyser (DMA). The selected particles were enumerated with a TSI $3772 \mathrm{CPC}\left(1 \mathrm{~L} \mathrm{~min}^{-1}\right.$ flow rate). The DMPS was used to determine the size distribution for the size range $0.01 \mu \mathrm{m}<D_{\mathrm{p}}<0.7 \mu \mathrm{m}$ (electrical mobility diameter) and a single scan over 37 size bins was completed in $12 \mathrm{~min}$. 
A particle's mobility equivalent diameter, $D_{\mathrm{mob}}$, is defined as the diameter of a sphere with the same electrical mobility as the particle. $D_{\text {mob }}$ is only equal to the volume equivalent diameter, $D_{\text {ve }}$, for spherical particles. Since $\mathrm{NaCl}$ and the other salts present in the artificial seawater used during our study form cubic and not spherical particles when aerosolised and dried, we have shape corrected the mobility diameters obtained using our DMPS. The relation between $D_{\text {mob }}$ and $D_{\text {ve }}$ of a particle is

$f=\frac{D_{\mathrm{ve}}}{D_{\mathrm{mob}}}=\frac{1}{\chi} \frac{C_{\mathrm{c}}\left(D_{\mathrm{ve}}\right)}{C_{\mathrm{c}}\left(D_{\mathrm{mob}}\right)}$,

where $f$ is the correction factor applied to each diameter measured, $\chi$ is the dynamic shape factor of the particle, and $C_{\mathrm{c}}$ is the Cunningham slip correction factor (Hinds, 1999). For spherical particles, $\chi$ has by definition the value 1 , while for $\mathrm{NaCl} \chi$ is equal to that of a cube (Hinds, 1999). For mobility diameters much greater than the mean free path of air, $\sim 0.06 \mu \mathrm{m}$, known as the continuum regime, $\chi$ for a cube is 1.08 (Hinds, 1999), while for particles smaller than this in the kinetic regime $\chi$ for a cube is $(6 / \pi)^{(1 / 3)}=1.23$ (Dahneke, 1973). However, since in the kinetic regime $C_{\mathrm{c}}$ also depends on $D_{\mathrm{mob}}$ and the ratio of $D_{\mathrm{ve}}$ to $D_{\mathrm{mob}}$ is related to the square root of $C_{\mathrm{c}}$, which is $\sim 1.1$, the use of 1.08 for all sizes will result in an inaccuracy of only a few percent. Therefore, we apply a $\chi$ of 1.08 across all sizes. We also assume that this value holds for the artificial sea salt used during our experiments and have used it to correct the size distributions obtained with our DMPS system to volume equivalent diameters.

\subsubsection{White-light optical particle size spectrometer}

Aerosol particle-laden air was vertically sampled and drawn directly upwards, without bends or contractions in the sample line, through $0.75 \mathrm{~m}$ of $1 / 2^{\prime \prime}$ stainless steel tubing and a custom made silica diffusion dryer to a Palas WELAS 2300 white-light aerosol spectrometer (WELAS; Palas GmbH) that was mounted directly above the sea spray chamber. This is an optical particle size spectrometer (OPSS) with a white-light source (Osram XBO-75 Xenon short arc lamp in the wavelength range of $\lambda \approx 350-750 \mathrm{~nm}$ ) that illuminates a measuring volume of $\sim 7 \mathrm{~cm}^{-3}$. Optical lenses collect the scattered light between 78 and $102^{\circ}$ with respect to the incident beam and direct it to a photomultiplier tube (PMT). The sensor is connected to the light source and detector via optical fibers, which minimises heat input from the lamp and temperature increase in the sensor. This instrument was used to obtain the aerosol size distribution for the size range $0.2 \mu \mathrm{m}<D_{\mathrm{p}}<10 \mu \mathrm{m}$ (polystyrene latex sphere optical equivalent diameter) at $1 \mathrm{~Hz}$, sizing particles in 59 bins.

Given that the OPSS instrument employs a white-light source, it should be less influenced by so-called "Mie wiggles" than OPSS instruments that use monochromatic light sources. Thus, the OPSS should be less affected by sizing ambiguities than a single wavelength OPSS.

The OPSS reports equivalent optical diameters that were calculated by the instrument's firmware using a preset empirical calibration curve based on polystyrene latex (PSL) sphere measurements. In order to account for systematic instrumental drifts caused by changes in the incident light intensity, changes of the PMT efficiency, or degradations of the optical fibers, we made periodic measurements of $0.85 \mu \mathrm{m}$ monodisperse CalDust (calibration dust provided by the manufacturer). Using these measurements the instruments firmware applied a correction factor to maintain a constant relation between scattered light intensity and optical diameter.

The probability that the OPSS will detect a particle is a function of the particle's size or cross section resulting in a size dependent counting efficiency. For particles close to the small end of the OPSS sizing range there is a decreased probability of detection or counting efficiency. Rosati et al. (2015) have determined the counting efficiency of the OPSS used in this study and their results were similar to those of Mullins et al. (2012). $100 \%$ counting efficiency is attained for all particles larger than $0.3 \mu \mathrm{m}$, and the counting efficiency increases to a maximum of $\sim 130 \%$. The raw counts obtained by the OPSS were multiplied by the reciprocal of the counting efficiency curve generated by Rosati et al. (2015) to correct for the counting efficiency of the instrument.

As with all OPSS instruments, the OPSS measurements depend on the wavelength-dependent complex refractive index of the sampled aerosol. It is this that determines the scattering response for particles of a given size and shape. Therefore, measurement of non-PSL aerosols such as sea salt aerosol particles with an OPSS factory calibrated with PSLs will manifest in a diameter shift of the size distribution due to differences in the refractive index of the materials. Since this diameter shift is likely to have a large influence on the aerosol particle surface and volume size distributions, we have converted the measured optical diameters to volume equivalent diameters by assuming that the sea salt aerosol particles had a refractive index of $m=1.54-0 i$ (Abo Riziq et al., 2007), which corresponds to the value of $\mathrm{NaCl}$ (compared to a refractive index of $m=1.588-0 i$ for the PSLs the instrument was calibrated with). This correction was conducted using the software provided by the manufacturer (PDAnalyze, Palas GmbH, Version No 2.024), which is based on instrument-specific Mie calculations.

As with the DMPS measurements, there is also an effect of particle shape on the OPSS measurements. Therefore, these measurements were also corrected, through the use of PALAS PDAnalyze software, assuming that the shape factor of 1.08 for $\mathrm{NaCl}$ holds for the artificial sea salt used during these experiments. 


\subsubsection{Temperature and humidity of the sampled aerosol}

The temperature and relative humidity $(\mathrm{RH})$ of the sample entering the DMPS, as well as the sheath air of the DMPS, were monitored using a Campbell Scientific HMP50 sensor. Although the relative humidity of the air entering the OPSS instrument was not measured directly, it is assumed that it was always well below $30 \%$ such that the sea spray aerosol had effloresced. This conclusion was made on the basis that all driers were of identical design and because the flow through the OPSS drier was significantly lower than the flow through the DMPS drier (OPSS: $0.5 \mathrm{~L} \mathrm{~min}^{-1}$; DMPS: $2 \mathrm{~L} \mathrm{~min}^{-1}$ ). Based upon the dimensions of the diffusion driers used and the flow rates of the various instruments, the residence time of the aerosol particle-laden air in the driers was $\sim 6 \mathrm{~s}$ and $\sim 1.5 \mathrm{~s}$ for the OPSS and DMPS instruments, respectively. The silica gel in each drier was replaced when the relative humidity measured at the inlet to the DMPS exceeded $25 \%$. Therefore, we report our aerosol in dry diameters.

\subsection{Experimental set-up}

Each experiment was conducted with artificial seawater (ASW) consisting of Sigma sea salt (Sigma Aldrich, S9883; mass fraction: $55 \% \mathrm{Cl}^{-}, 31 \% \mathrm{Na}^{+}, 8 \% \mathrm{SO}_{4}^{2-}, 4 \% \mathrm{Mg}^{2+}$, $1 \% \mathrm{~K}^{+}, 1 \% \mathrm{Ca}^{2+},<1 \%$ other) rehydrated to an absolute salinity of $35 \mathrm{~g} \mathrm{Kg}^{-1}$ using DIW. We subjected our artificial seawater to a purification process in the same manner as previously described by Salter et al. (2014). This consisted of activated charcoal treatments, artificial UV exposures and hydrogen peroxide $\left(\mathrm{H}_{2} \mathrm{O}_{2}, 30 \%\right.$ solution, no stabiliser) additions. Here $\mathrm{H}_{2} \mathrm{O}_{2}$ acted as an oxidising agent to remove organic matter.

Manipulating the water temperature in the sea spray chamber could potentially have changed gas saturation levels in the water. Since there has been speculation in the literature that sub- or super-saturations of atmospheric gases in seawater might affect particle production through changes to the bubble population (e.g. Stramska et al., 1990), we conducted constant temperature experiments to ensure that gas saturations were in thermodynamic equilibrium with the headspace of the sea spray chamber. Once the artificial seawater purification procedure was complete, the water temperature was held constant at a series of values between -1 and $30^{\circ} \mathrm{C}$ whilst measurements of the aerosol generated were conducted. The water temperatures investigated were $-1,3$, $5,8,10,20$, and $30^{\circ} \mathrm{C}$. At each water temperature aerosol measurements were conducted over a period $\geq 2 \mathrm{~h}$ following a period of at least $12 \mathrm{~h}$ at the desired temperature. Measurements of oxygen concentration in the seawater confirmed that gas saturations were in thermodynamic equilibrium and the oxygen percent saturations were not significantly different between the experiments. The mean oxygen saturation across all experiments was $111 \%$ with a standard deviation of $1 \%$ (the reported accuracy of the Aanderaa oxygen optode 4175 is to within $<5 \%$ saturation), within the range of anomalies typically encountered in ocean surface waters (Najjar and Keeling, 1997).

The second phase of the experiment consisted of measurements of the sea spray aerosol particles generated whilst the temperature of the water was slowly ramped downward from 30 to $2{ }^{\circ} \mathrm{C}$ over a period of $29 \mathrm{~h}$. This second phase was conducted $24 \mathrm{~h}$ after the first phase of experiments were completed. In the interim period the chamber was kept closed with a constant inflow of zero-particle air and the same water was used for both experiments. At no point during the seawater cooling experiment was the water undersaturated with respect to $\mathrm{O}_{2}$ (see Supplement), nor was it significantly different than the mean of the constant temperature experiments (mean oxygen saturation: $111 \%$ ).

In order to obtain estimates of the particle size distributions as a function of water temperature during this experiment the data were binned at a resolution of $1{ }^{\circ} \mathrm{C}$. Here the data from the DMPS system and the OPSS have been combined following corrections for particle shape and refractive index, respectively. The two instruments both provide sizeresolved particle number in the dry diameter range between $\sim 0.2$ to $0.7 \mu \mathrm{m}$. Given that for particles close to the small end of the OPSS sizing range there is a decreased probability of detection and that an increasing number of particles close to upper size range of the DMPS system will have been influenced by the $\sim 1 \mu \mathrm{m}$ impactor placed prior to it, we have chosen to use the DMPS measurements in the range 0.01 to $0.45 \mu \mathrm{m}$ and the OPSS measurements in the range 0.45 to $10 \mu \mathrm{m}$.

\section{Results}

\subsection{Measured number size distributions during the constant temperature experiments}

Over the 0.01 to $10 \mu \mathrm{m}$ diameter size range covered by the DMPS system and OPSS instrument, when represented in the form $\mathrm{d} N / \mathrm{d} \log D_{\mathrm{p}}$, the size distributions obtained during the constant water temperature experiments exhibit three modes (Fig. 2). A noteworthy observation is the apparent lack of agreement between the DMPS measurements and the OPSS measurements in the particle size range where they overlap. Most likely the DMPS instrument was increasingly influenced by particle losses due to the system tubing and the impactor placed before it in its upper sizing range. It should be borne in mind that the particle size range over which the instruments disagree is not dominating $\mathrm{d} N / \mathrm{d} \log D_{\mathrm{p}}, \mathrm{d} S / \mathrm{d} \log D_{\mathrm{p}}$, or $\mathrm{d} V / \mathrm{d} \log D_{\mathrm{p}}$; therefore, it is unlikely to influence the number fluxes, optical properties, or mass fluxes of the sea spray source function derived later in this study. 
(a)

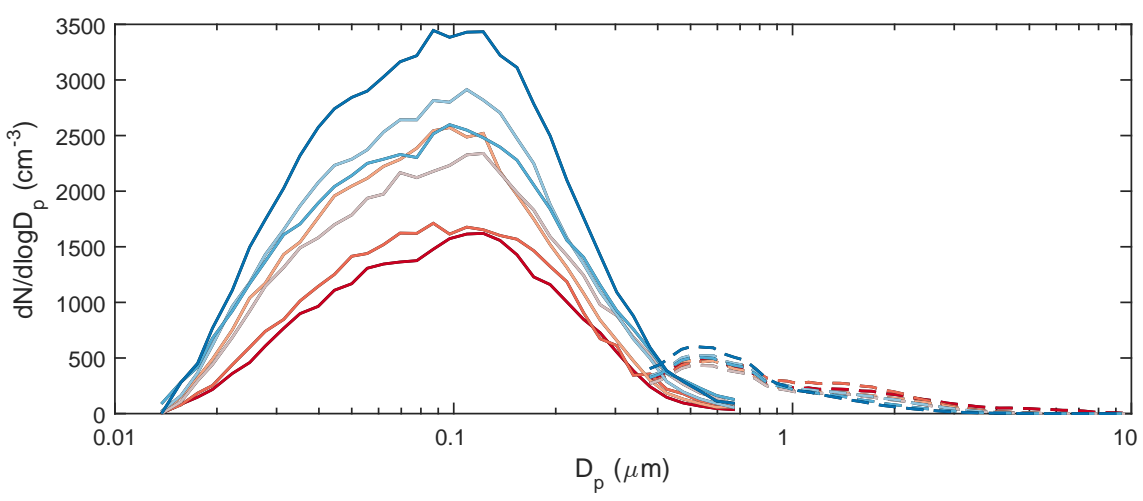

(b)

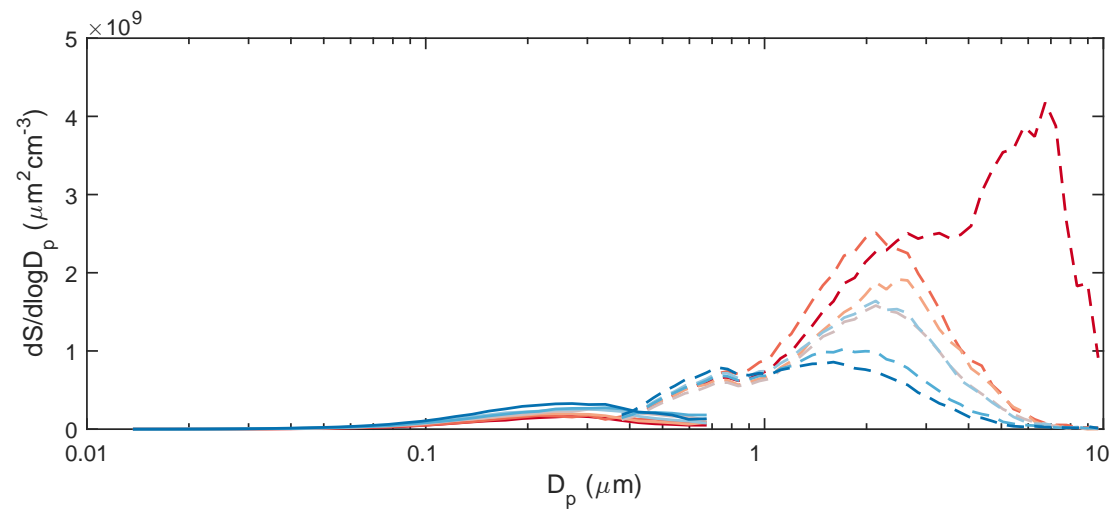

(c)

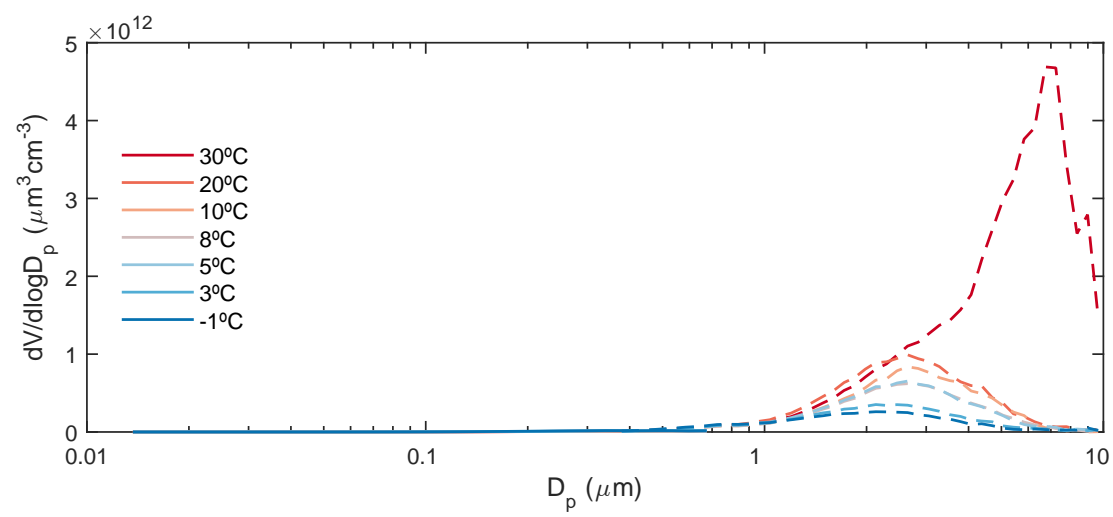

Figure 2. Mean particle (a) number size distribution, (b) surface size distribution, and (c) volume size distribution measured at different water temperatures. The solid lines represent the DMPS measurements $\left(D_{\mathrm{p}}<0.7 \mu \mathrm{m}\right.$ electrical mobility diameter), while the dashed lines show the OPSS data $\left(D_{\mathrm{p}}>0.35 \mu \mathrm{m}\right.$ optical equivalent diameter when $\left.m=1.54-0 i\right)$.

Following correction for the effect of shape, the DMPS system data exhibited a single mode centred close to $0.1 \mu \mathrm{m}$ when plotted in the form $\mathrm{d} N / \mathrm{d} \log D_{\mathrm{p}}$. The magnitude of this mode decreased as the water temperature was increased between -1 and $30^{\circ} \mathrm{C}$. Following correction for the effect of both shape and refractive index, the data obtained using the OPSS exhibited two modes when plotted in the form $\mathrm{d} N / \mathrm{d} \log D_{\mathrm{p}}$. One was centred around $0.55 \mu \mathrm{m}$ and another was centred around $1.5 \mu \mathrm{m}$. The mode centred around $0.55 \mu \mathrm{m}$ exhibited similar behaviour to the mode centred around $0.1 \mu \mathrm{m}$ in that its magnitude decreased as the water temperature increased. However, the mode centred around $1.5 \mu \mathrm{m}$ exhibited different behaviour in that its magnitude also increased as the water temperature was increased. This effect is much more prominent when the size distribution is plotted in the form of the particle surface size distribution $\left(\mathrm{d} S / \mathrm{d} \log D_{\mathrm{p}}\right)$ or particle volume size distribution $\left(\mathrm{d} V / \mathrm{d} \log D_{\mathrm{p}}\right)$, which both assume that the particles are spherical (Fig. 2). 
Also noteworthy is the observation that the data obtained at $30^{\circ} \mathrm{C}$ appears to show a sudden shift in the size distribution to larger sizes. Although we cannot discount that this effect is real, since we observe this effect only at a water temperature of $30^{\circ} \mathrm{C}$ suggests that this is more likely to have been a measurement artefact. Given that at a water temperature of $30^{\circ} \mathrm{C}$ in the chamber the air temperature was only slightly lower and the sea spray chamber headspace had an $\mathrm{RH}$ of $\sim 98 \%$, the absolute water content will have been high. This combined with the observed increase in the number of larger particles $(>1 \mu \mathrm{m})$ at this temperature relative to lower water temperatures may mean that despite the fact that the RH at the inlet to the OPSS was below the efflorescence point of the particles, assuming they were mainly $\mathrm{NaCl}$, the particles may not have had adequate time to fully effloresce and thus could have still been partially liquid. The rate at which the particles were crystallising may also have changed, a factor which is known to effect the ultimate shape $\mathrm{NaCl}$ particles take when dried (Wang et al., 2010).

\subsection{Measured number size distributions during the temperature ramp experiments}

Measured $\mathrm{d} N / \mathrm{d} \log D_{\mathrm{p}}$ was very similar to the constant temperature experiments, consisting of three modes centred at dry diameters of $\sim 0.1, \sim 0.55$, and $\sim 1.5 \mu \mathrm{m}$ (see Supplement). The two smallest modes decreased in magnitude with increased water temperature whilst the mode at the largest dry diameter exhibited opposite behaviour and increased in number as the water temperature was increased. Once again this trend is much more apparent when the size distribution is presented in the forms $\mathrm{d} S / \mathrm{d} \log D_{\mathrm{p}}$ and $\mathrm{d} V / \mathrm{d} \log D_{\mathrm{p}}$. The sudden shift towards larger particles observed in the constant temperature experiments was also apparent during the temperature ramp experiments. However, it appeared at a slightly lower temperature of $\sim 23^{\circ} \mathrm{C}$.

Comparison of the constant temperature experiments and the temperature ramp experiments is facilitated in Fig. 3. The integrated total particle number concentration (integrated across the size range 0.01 to $10 \mu \mathrm{m}$ ) in the temperature ramp experiments was not significantly different to the constant temperature experiments. Figure 3 d plots the effective radius $\left(r_{\text {eff }}\right)$ of both the constant temperature experiments and the temperature ramp experiment as a function of water temperature:

$r_{\text {eff }}=\frac{3 V}{A}$,

where $V$ is the total integrated particle volume and $A$ is the total integrated particle surface area (assuming spherical particles). The effective radius of both the constant temperature experiments and the temperature ramp experiment were also very similar at comparable water temperatures.

Given the observed similarity between the constant water temperature experiments and the water temperature ramp experiments, as well as the higher water temperature resolution of the latter experiments, we have chosen to use the data from only the temperature ramp experiments to generate a new inorganic sea spray aerosol parameterisation as a function of water temperature in the following section.

\section{Derivation of a model parameterisation of the sea spray aerosol production flux}

\subsection{Air entrainment as a function of wind speed}

We have combined the number of particles in a unit logarithmic interval of $D_{\mathrm{p}}$ produced per unit time $\left(p\left(D_{\mathrm{p}}, T\right)\right)$ as a function of seawater temperature measured during our experiments with measurements of the air entrained by the plunging jet as a function of temperature presented in Salter et al. (2014). This approach is based on the assumption that all air entrained into the water column detrains as bubbles that produce particles. This approach also assumes that there is no dependence of oceanic air entrainment on SST and does not make allowance for other factors that may affect air entrainment flux such as breaking wave strength or sea state. As with nearly all laboratory-based studies of sea spray aerosol production, another critical assumption of our approach is that the size distribution of the aerosol produced is constant across all wind speeds.

Using this approach, the rate of particle production per unit volume of entrained air as a function of water temperature during our experiments $\left(f_{\tau}\left(D_{\mathrm{p}}, T\right)\right)$ is defined as

$f_{\tau}\left(D_{\mathrm{p}}, T\right)=\frac{p\left(D_{\mathrm{p}}, T\right)}{\tau(T)}$,

where $p\left(D_{\mathrm{p}}, T\right)$ is the number of particles in a unit logarithmic interval of $D_{\mathrm{p}}$ produced per unit time as a function of water temperature $(T)$, and $\tau(T)$ is the rate of air entrainment in $\mathrm{m}^{3} \mathrm{~s}^{-1}$ as a function of water temperature. Figure 4 depicts the rate of particle production per unit volume of entrained air determined from the temperature ramp data (see Sect. 3.2) using this approach.

In order to estimate the size-resolved oceanic interfacial sea spray aerosol production flux, $f_{\text {int }}$, we have combined the size-resolved particle production rate per unit volume of entrained air from Eq. (3) with an estimate of the entrainment flux of air into the oceanic water column in the same manner as described by Long et al. (2011):

$f_{\text {int }}\left(D_{\mathrm{p}}, T\right)=f_{\tau}\left(D_{\mathrm{p}}, T\right) F_{\mathrm{ent}}$,

where $F_{\text {ent }}$ is the dependence of the air entrainment flux into the oceanic water column on wind speed measured at $10 \mathrm{~m}$ height $\left(U_{10}\right)$.

As discussed by Long et al. (2011), the air entrainment flux into the water column $\left(F_{\text {ent }}\right)$ can be estimated from

$F_{\text {ent }}=\alpha \epsilon_{\mathrm{d}}$, 
(a)

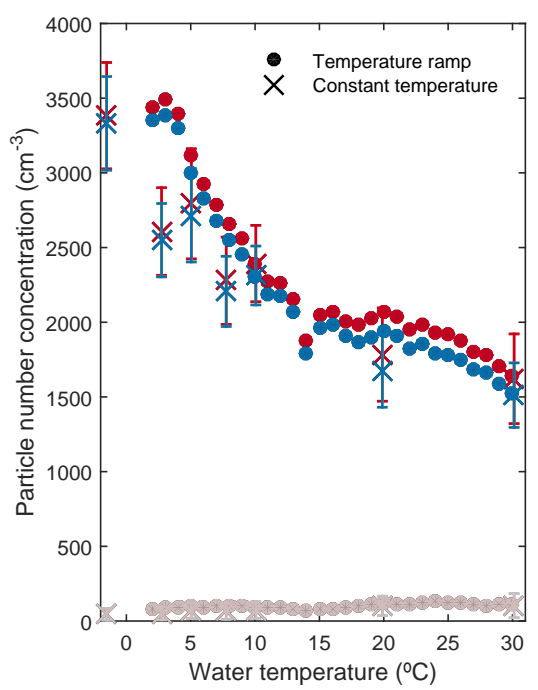

(c)

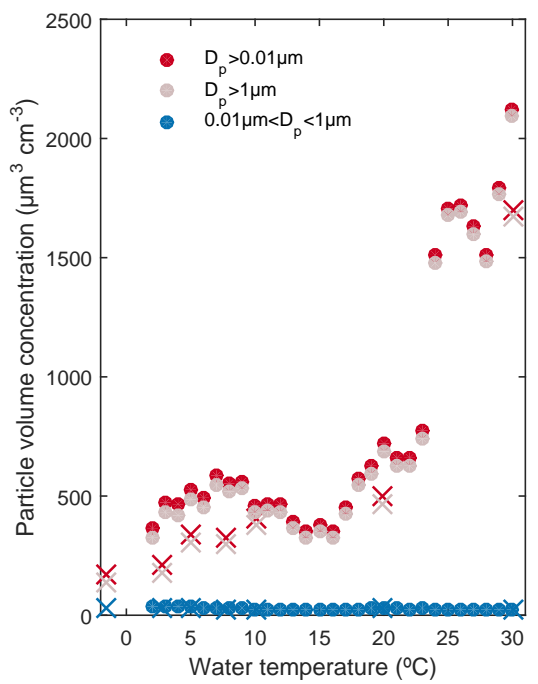

(b)

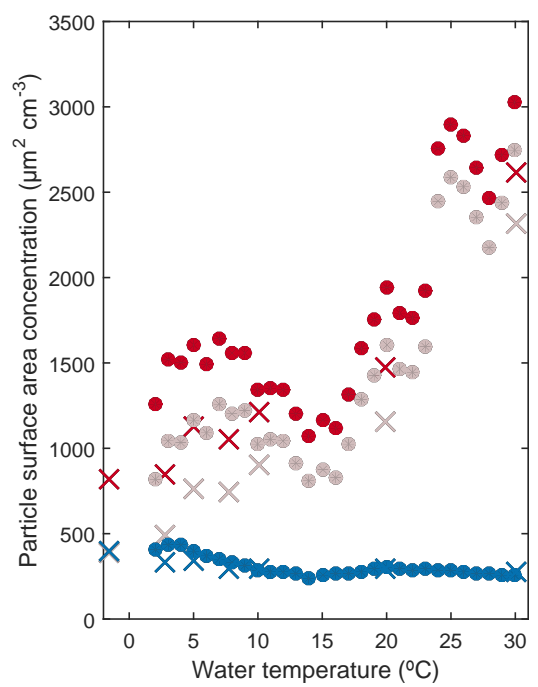

(d)

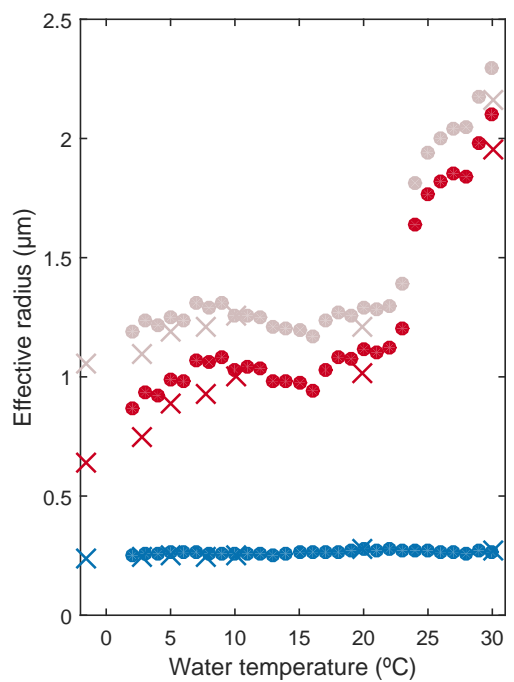

Figure 3. Integrated (a) number, (b) surface, and (c) volume as a function of water temperature for the constant water temperature experiments (crosses) and during the temperature ramp experiment (circles). One standard deviation $(1 \sigma)$ is shown for the integrated number concentration during the constant temperature experiments. Panel (d) plots the effective radius as a function of water temperature for all experiments.

where $\epsilon_{\mathrm{d}}$ is the rate of energy dissipation by wave breaking in $\mathrm{W} \mathrm{m}^{-2}$ and $\alpha$ is the ratio of the volume of air entrained by breaking waves to the energy dissipated by the wind-wave field through wave breaking. As presented by Long et al. (2011), initially we assumed a range of $(4 \pm 2) \times 10^{-4} \mathrm{~m}^{3} \mathrm{~J}^{-1}$ for $\alpha$ and that $\epsilon_{\mathrm{d}}$ varies as a function of wind speed as $(5 \pm 1) \times 10^{-5}\left(U_{10}\right)^{3.74} \mathrm{~W} \mathrm{~m}^{-2}$ giving

$F_{\text {ent }}=(2 \pm 1) \times 10^{-8} \cdot\left(U_{10}\right)^{3.74}$,

where $F_{\text {ent }}$ is in $\mathrm{m}^{3} \mathrm{~m}^{-2} \mathrm{~s}^{-1}$. However, this resulted in unrealistic over-production of sea spray aerosol at low latitudes in the Southern Hemisphere when implemented in the Norwegian Earth system model (NorESM) (see Sect. 7). Numerous existing sea spray aerosol parameterisations based upon the whitecap method utilise a wind speed dependence of $\left(U_{10}\right)^{3.41}$ with recent studies advocating even lower wind speed dependencies with a smaller exponent for $U_{10}$ (e.g. Callaghan, 2013). Given this we have kept the scaling to air entrainment the same as that used by Long et al. (2011) but use a lower wind speed dependency of $\left(U_{10}\right)^{3.41}$, which is the same value used by Kirkevåg et al. (2013). This results in a final dependency of air entrainment on wind speed of 


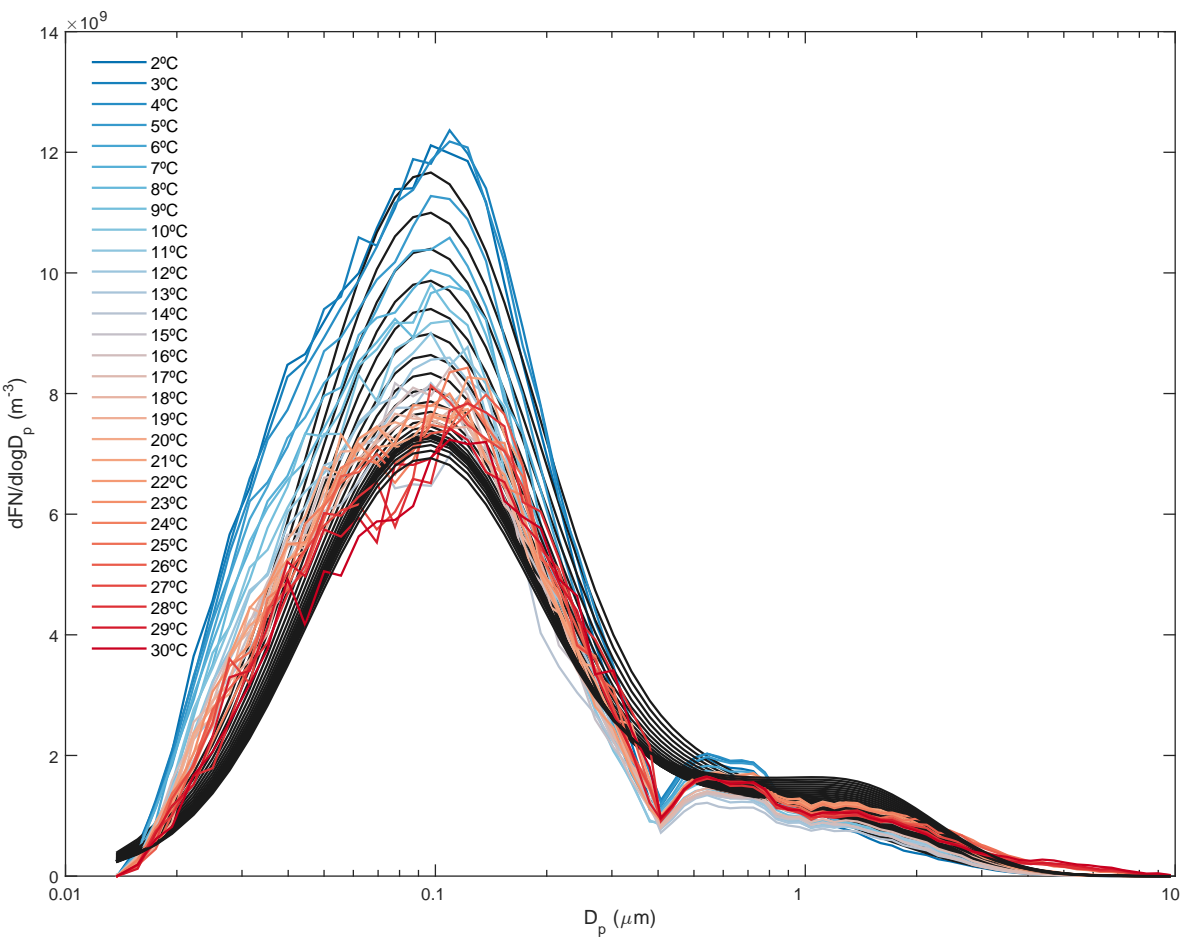

Figure 4. Mean aerosol number effective flux distribution of the corrected temperature ramp data (coloured lines) and corresponding lognormal fits constrained by fixed modal diameters and geometric standard deviations (black lines).

$F_{\text {ent }}=(2 \pm 1) \times 10^{-8} \cdot\left(U_{10}\right)^{3.41}$,

where $F_{\text {ent }}$ is in $\mathrm{m}^{3} \mathrm{~m}^{-2} \mathrm{~s}^{-1}$.

Given that this change is arbitrary we would urge that the modelling community first implement the parameterisation using the larger exponent of $\left(U_{10}\right)^{3.74}$ since this has a more sound physical basis. If the model does not compare well with observed sea spray concentrations or data from remote sensing, re-tuning of uncertain parameters in the model (e.g. prescribed scavenging coefficients for SSA), within the range of uncertainty for those particular parameters, may improve the model results. If not, this single exponent value (3.74) can then be changed as and when new research on the dependence of air entrainment upon wind speed is available in the literature.

\subsection{Effective vs. interfacial sea spray aerosol fluxes}

The aim of this study is to provide a parameterisation of sea spray aerosol production to represent the production flux in atmospheric chemical transport models or global circulation models. Usually such models have their lowest atmospheric layer at $10 \mathrm{~m}$ and often much higher (e.g. 100 and $180 \mathrm{~m}$ in the FLEXible PARTicle (FLEXPART) dispersion model and NorESM, respectively). Therefore, knowledge of the size distribution of particles that attain significant height in the atmosphere, often referred to as the effective flux, is required.
Since the inlets to the aerosol instrumentation used during this study were sited $\sim 30 \mathrm{~cm}$ above the water surface, we have determined the flux of particles that reached this height, often referred to as the interfacial flux. As such, consideration should be given to the difference between the effective production flux and the interfacial production flux measured at $\sim 30 \mathrm{~cm}$.

Using an approach described by Lewis and Schwartz (2004) we have attempted to convert the interfacial fluxes measured in the sea spray chamber utilised during this study to effective fluxes at $10 \mathrm{~m}$ height. This approach is outlined in detail in the Supplement accompanying this work. Since the ratio of effective fluxes to interfacial fluxes depends on both particle size and wind speed, computation of the effective sea spray aerosol particle flux should take into account both variables. However, since it is non-trivial to add a sizedependent correction to the model that can account for the difference between effective and interfacial fluxes, we have converted the temperature-dependent interfacial fluxes measured during our study to temperature-dependent effective fluxes based upon a single wind speed $\left(U_{10}\right)$ of $7 \mathrm{~m} \mathrm{~s}^{-1}$, approximately the global average wind speed over the ocean. An implication of this assumption is that effective fluxes will be overestimated at wind speeds below $7 \mathrm{~m} \mathrm{~s}^{-1}$ and underestimated at wind speeds above $7 \mathrm{~m} \mathrm{~s}^{-1}$. 


\subsection{Size distribution as a function of temperature}

Using the data presented in Sect. 3.2 we have generated a temperature-dependent sea spray source function. Since many Earth system models utilise modal modules as input for aerosol emissions to limit computation time, we present our source function in this manner.

The effective particle production flux (see Fig. 4) has been parameterised by fitting the $1{ }^{\circ} \mathrm{C}$ binned interfacial number fluxes obtained during the temperature ramp experiments corrected to an effective flux at $7 \mathrm{~m} \mathrm{~s}^{-1}$ wind speed, to the sum of three log-normal distributions of the form:

$$
\begin{aligned}
& \frac{\mathrm{d} F}{\mathrm{~d} \log D_{\mathrm{p}}}= \\
& \sum_{i=1}^{3} \frac{N_{i}}{\sqrt{2 \pi} \log \sigma_{i}} \exp \left(-\frac{1}{2} \frac{\left(\log D_{\mathrm{p}}-\log \bar{D}_{\mathrm{mod}, i}\right)^{2}}{\left(\log \sigma_{i}\right)^{2}}\right),
\end{aligned}
$$

where $N_{i}$ is the number production flux, $\bar{D}_{\text {mod, } i}$ is the mode (median) diameter, $\sigma_{i}$ is the standard deviation of the $i$ th lognormal mode, and log is the logarithm with base 10 .

Least-squares polynomial curve fitting was conducted to allow for the estimation of the number production flux $\left(N_{i}\right)$ of the log-normal modes, with fixed modal diameters and geometric standard deviations, as a function of water temperature. Therefore, in the final form of the parameterisation, the $N_{i}$ of each of the three log-normal modes is a cubic function of sea surface temperature:

$N_{i}=F_{\operatorname{ent}\left(U_{10}\right)} \cdot\left(A_{i} \cdot T^{3}+B_{i} \cdot T^{2}+C_{i} \cdot T+D_{i}\right)$,

where $F_{\mathrm{ent}\left(U_{10}\right)}$ is the volume of air entrained per unit area per unit time as a function of $U_{10}$ (Eq. 7) and $\mathrm{T}$ is the sea surface temperature in Celsius. Table 2 describes the details of the three modes and the modal emission coefficients for use in Eq. (9).

Overlaid in black in Fig. 4 are the log-normal fits for each water temperature based on the values given in Table 2 and Eq. (9). Although there is a tendency for the fits to underestimate the magnitude of the mode centred at $0.095 \mu \mathrm{m}$, the fits are able to account for most of the variability in the measured number effective flux distributions, with the coefficient of determination $\left(R^{2}\right)$ values of the fits ranging between 0.94 and 0.97 for the effective number fluxes across the range of temperatures 2 to $30^{\circ} \mathrm{C}$; however, comparison between the predicted surface area fluxes and those measured highlight discrepancies. Between 2 and $22^{\circ} \mathrm{C}$, the correlation between predicted surface area fluxes and those measured is generally good with $R^{2}$ values between 0.96 and 0.99 . However, at water temperatures higher than $22^{\circ} \mathrm{C}$ the correlation between predicted surface area fluxes and those measured becomes much poorer, with $R^{2}$ values decreasing monotonically from 0.70 at $23^{\circ} \mathrm{C}$ to 0.21 at $30^{\circ} \mathrm{C}$. This disconnect results from the fact that the measured particles increase considerably in size, an effect which the fits, constrained to constant modal diameter and geometric standard deviations, cannot account for. The observation that a transition to larger particle sizes occurred at a water temperature of $\sim 23^{\circ} \mathrm{C}$ was discussed in detail in Sect. 3.1 with the conclusion that we cannot exclude that the particles had not fully effloresced at these higher water temperatures. Given this, we have assumed that the small increase in the number of particles with dry diameters greater than $1 \mu \mathrm{m}$ observed as water temperatures increased from 2 to $22^{\circ} \mathrm{C}$ continued at higher water temperatures by simply extrapolating the increase in the number production flux in the fitted mode centred at $1.5 \mu \mathrm{m}$ observed in the water temperature between 2 and 22 up to $30^{\circ} \mathrm{C}$.

The source function estimated during this study is compared with a variety of source functions from other recent studies for wind speeds of $10 \mathrm{~m} \mathrm{~s}^{-1}$ in Fig. 5a (Mårtensson et al., 2003; Gong, 2003; Long et al., 2011; Clarke et al., 2006; Ceburnis et al., 2014) as well as the previous source function implemented in NorESM described by Kirkevåg et al. (2013). The latter source function is a slight modification of the previous sea spray aerosol treatment in NorESM1M introduced by Struthers et al. (2013), which in turn was based on the Mårtensson et al. (2003) source function. Therefore, it includes a dependence on sea surface temperatures. In contrast, the source functions of Gong (2003), Long et al. (2011) and Clarke et al. (2006) do not incorporate a dependence on sea surface temperature and were presumably derived at water temperatures somewhere close to either room temperature (in the case of Long et al., 2011; Gong, 2003) or to the sea surface temperature in coastal Hawaii (in the case of Clarke et al., 2006), since none of the studies make specific reference to the water temperature. All the source functions are shown for particle sizes normalised to dry diameter. The source function obtained during this study lies within the range of the other functions for all particle sizes measured.

Assuming the measured sea spray aerosol particles are spherical, it is possible to integrate the sea spray aerosol mass flux to obtain mass emissions as a function of wind speed and sea surface temperature. This can then be compared to observations as well as previously published sea spray aerosol source functions. Sea spray aerosol mass emissions, $\bar{F}$, can be obtained as follows:

$\bar{F}=\frac{\pi}{6} \rho_{\mathrm{ss}} \int_{D_{\mathrm{p}, 1}}^{D_{\mathrm{p}, 2}} \frac{\mathrm{d} F}{\mathrm{~d} \log D_{\mathrm{p}}} D_{\mathrm{p}}{ }^{3} \mathrm{~d} \log D_{\mathrm{p}}$,

where $\rho_{\mathrm{SS}}$ is the density of sea salt $\left(2.16 \mathrm{~g} \mathrm{~cm}^{-3}\right)$ assuming it is similar to that of $\mathrm{NaCl}$. Measurements of sea spray aerosol mass are often obtained using aerosol mass spectrometers (e.g. Ceburnis et al., 2014), which determine the vacuum aerodynamic diameter, $D_{\text {va }}$. When such instruments obtain mass estimates for particles with dry diameters smaller than $1 \mu \mathrm{m}, D_{\mathrm{va}}=0.05-1 \mu \mathrm{m}$, which is equivalent to $D_{\mathrm{p}}=0.029-0.580 \mu \mathrm{m}$. Figure $5 \mathrm{~b}$ shows $\bar{F}$ integrated 

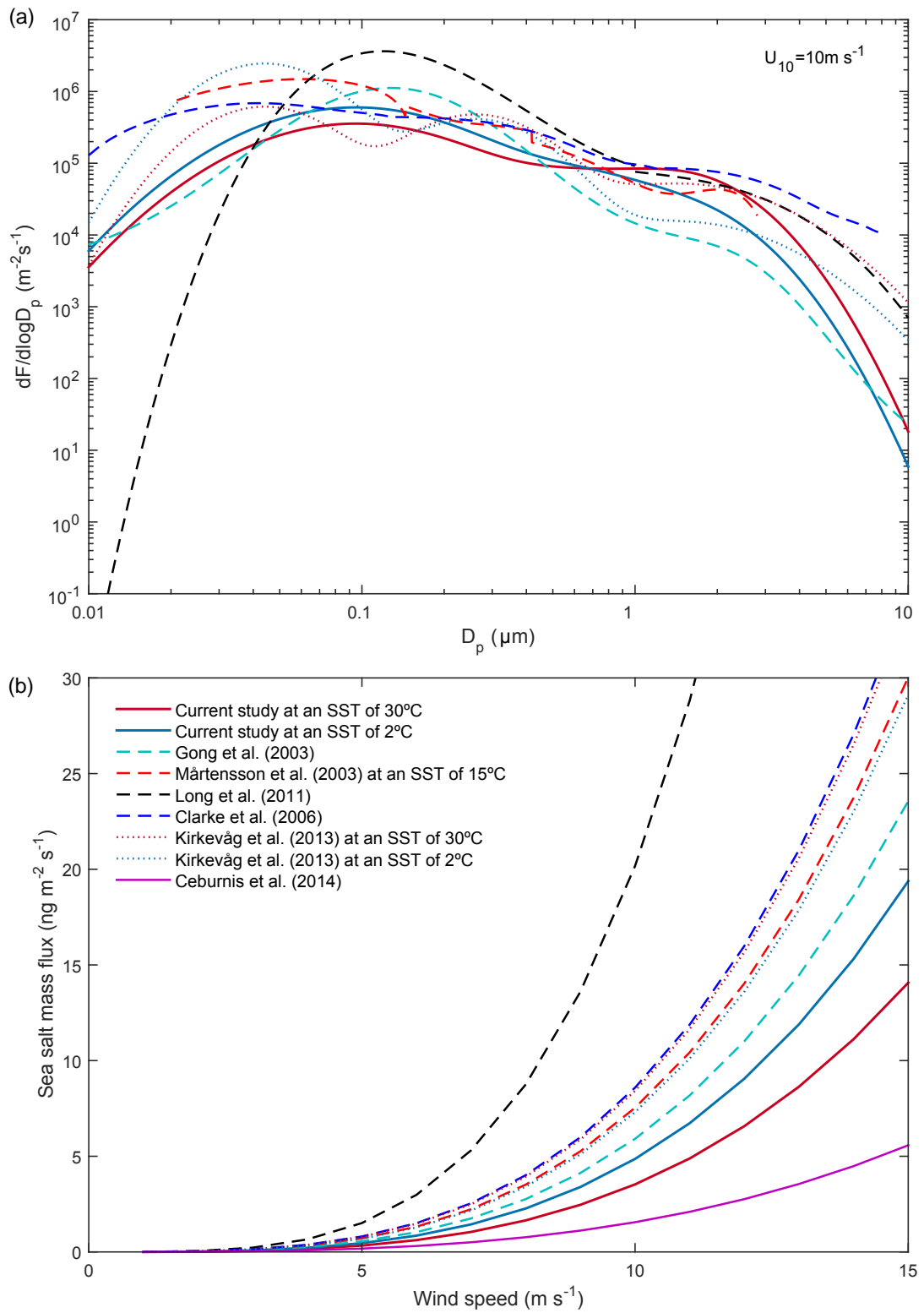

Figure 5. (a) The here derived sea spray source function $\left(\mathrm{d} F / \mathrm{d} \log D_{\mathrm{p}}\right)$ for three different sea surface temperatures compared to the parameterisations of Mårtensson et al. (2003), Gong (2003), Long et al. (2011), and Clarke et al. (2006), as well as the source function previously implemented in NorESM described by Kirkevåg et al. (2013) (see legend in b). Panel (b) plots integrated $\left(0.029 \mu \mathrm{m}<D_{\mathrm{p}}<0.580 \mu \mathrm{m}\right)$ sea salt mass fluxes as a function of wind speed measured at $10 \mathrm{~m}$ height for the same parameterisations shown in panel (a) as well as the fit to measured data reported by Ceburnis et al. (2014).

across the size range: $0.029 \mu \mathrm{m}<D_{\mathrm{p}}<0.580 \mu \mathrm{m}$ as a function of wind speed for the sea spray source function derived during this study at sea surface temperatures of 2,15 , and $30^{\circ} \mathrm{C}$, a number of previously published source functions, the source function previously implemented in NorESM described by Kirkevåg et al. (2013), as well as a fit to measurements made at the Mace Head coastal station recently published by Ceburnis et al. (2014). It is clear from these figures that the previously published source functions, including the source function previously implemented in NorESM, predict much higher sea salt mass emissions (for particles with dry diameters smaller than $1 \mu \mathrm{m}$ ) to the extent that at $U_{10}=10 \mathrm{~m} \mathrm{~s}^{-1}$ they are a factor of 2-3 higher. The Long et al. (2011) source function predicts sea salt mass emissions for particles with dry diameters smaller than $1 \mu \mathrm{m}$ that are an order of magnitude higher at $U_{10}=10 \mathrm{~m} \mathrm{~s}^{-1}$ in part due to its strong wind speed dependence of $\left(U_{10}\right)^{3.74}$. This appears to support our decision to reduce the wind speed dependence of our function down from $\left(U_{10}\right)^{3.74}$ to $\left(U_{10}\right)^{3.41}$. Indeed, the 
Table 1. The modal diameters and geometric standard deviations $(\sigma)$ for the previous sea spray aerosol parameterisation implemented in NorESM (Kirkevåg et al., 2013).

\begin{tabular}{crr}
\hline Mode & $\begin{array}{r}\text { Modal } \\
\text { diameter } \\
(\mu \mathrm{m})\end{array}$ & \\
\hline 1 & 0.044 & 1.59 \\
2 & 0.26 & 1.59 \\
3 & 1.48 & 2.0 \\
\hline
\end{tabular}

new source function presented in this study compares much better with the measurements of Ceburnis et al. (2014).

\section{Model simulations}

\subsection{The FLEXPART Lagrangian particle dispersion model}

The FLEXPART Lagrangian particle dispersion model (Stohl et al., 2005) has been used to simulate sea spray aerosol transport from its source to a series of observation sites where chemical analysis of $\mathrm{Na}^{+}$on aerosol filter samples has been conducted. This model computes the trajectories of particles in the atmosphere to describe the transport and turbulent diffusion of tracers. In this study particles were released from the observation sites at a constant rate of 15000 particles per hour during every measurement sampling interval and followed backwards in time for 20 days. When run in backward mode tracing mass concentrations the output of the model is an emission sensitivity in seconds as a function of space $\left(1^{\circ} \times 1^{\circ}\right.$ with variable vertical resolution) and time (every $3 \mathrm{~h}$ ). Here emission sensitivity can be thought of as a statistical measure of the fraction of time that an air mass has spent over a specific area of ocean. By multiplying the emission sensitivity in the lowest model layer $(100 \mathrm{~m})$ by a source flux, the source contribution is obtained. When integrated over all grid cells and $3 \mathrm{~h}$ intervals, this provides the simulated sea spray aerosol concentration at the measurement point averaged over the sampling interval. Further detail on the manner in which we run this model can be found in Grythe et al. (2014).

In order to facilitate comparison with other commonly deployed sea spray source functions, four log-normal modes with modal diameters of $1.3,9.4,13.6$, and $17.8 \mu \mathrm{m}$ and corresponding geometric standard deviations of $1.350,1.100$, 1.075 , and 1.050 were used to approximate the source function presented in Sect. 4.

FLEXPART modelled sea spray aerosol concentrations using the parameterisation presented in this study are compared with the database of observed sea spray aerosol concentrations compiled by Grythe et al. (2014). This consists of ob- servational data obtained at 21 monitoring sites and on-board ships during 11 research cruises (see Table 1 in Grythe et al., 2014) and totals over 20000 observations distributed over the global oceans.

\subsection{The Norwegian Earth system model}

We have used a modified first version of the Norwegian Earth System Model, NorESM1-M (Bentsen et al., 2013; Iversen et al., 2013; Kirkevåg et al., 2013). This model is run with intermediate atmospheric resolution $\left(1.9^{\circ} \times 2.5^{\circ}\right)$ and is based on the Community Climate System Model v4 (CCSM4) developed at the National Center for Atmospheric Research (NCAR) (Gent et al., 2011). The model was set up to run in the same manner as described by Kirkevåg et al. (2013) with only slight modifications to the version of the atmospheric model, CAM4-Oslo. The model was set up using prescribed sea surface temperatures and run in offline mode, so that changes in aerosol treatment do not affect the meteorology.

The aerosol module in the atmospheric model, CAM4Oslo, describes the size-resolved aerosol physics and transport of 20 aerosol components and combines a life-cycle model that handles the emissions, processing and transport of aerosol mass with a physics scheme with look-up tables calculated by an offline microphysics model. The look-up tables are used to compute the bulk (from size-resolved) physical and optical properties of the aerosol population. The differences introduced in the aerosol schemes compared to Kirkevåg et al. (2013) are the modified modal median diameters and standard deviations of the log-normal (and dry) sea spray size distributions at the point of emission. The previous modal mean diameters and standard deviations from the parameterisation by Kirkevåg et al. (2013) are listed in Table. 1. The parameters for the new parameterisation are listed in Table 2.

\section{Comparison to a Lagrangian particle dispersion model}

Using European Centre for Medium-Range Weather Forecasts (ECMWF) wind fields over a $25 \mathrm{yr}$ period, sea spray aerosol production was calculated using the source function presented here as well as a number of source functions more commonly deployed in large-scale models. Annual mean global sea spray aerosol production was $5.9 \pm 0.2 \mathrm{Pg} \mathrm{yr}^{-1}$, where the plus or minus value represents only the interannual variability. Although this is at the low end of the range of estimates presented by Grythe et al. (2014) of between 1.83 and $2444 \mathrm{Pg} \mathrm{yr}^{-1}$ it compares favourably with the median of the 22 source functions of $5.91 \mathrm{Pg} \mathrm{yr}^{-1}$ (Grythe et al., 2014). For comparison the source functions of Monahan et al. (1986) (defined only up to $D_{\mathrm{p}}=0.8 \mu \mathrm{m}$ ), Gong (2003) (an extrapolation of Monahan et al., 1986), and 
Table 2. Modal diameters, geometric standard deviations $(\sigma)$, and the polynomial coefficients for the number flux $\left(N_{i}\right)$ of each of the three log-normal modes in the here derived parameterisation (Eq. 9).

\begin{tabular}{rrrrrrr}
\hline Mode & $\begin{array}{r}\text { Modal } \\
\text { diameter } \\
(\mu \mathrm{m})\end{array}$ & $\sigma$ & $A_{i}$ & $B_{i}$ & $C_{i}$ & $D_{i}$ \\
& & & & & \\
\hline 1 & 0.095 & 2.10 & $-5.2168 \times 10^{5}$ & $3.31725 \times 10^{7}$ & $-6.95275 \times 10^{8}$ & $1.0684 \times 10^{10}$ \\
2 & 0.6 & 1.72 & 0.00 & $7.374 \times 10^{5}$ & $-2.4803 \times 10^{7}$ & $7.7373 \times 10^{8}$ \\
3 & 1.5 & 1.60 & 0.00 & $1.4210 \times 10^{4}$ & $1.4662 \times 10^{7}$ & $1.7075 \times 10^{8}$ \\
\hline
\end{tabular}

Sofiev et al. (2011)produced 4.5, 4.6, and $2.6 \mathrm{Pg} \mathrm{yr}^{-1}$, respectively. Further comparison to existing source functions can be made using Table 2 in Grythe et al. (2014).

Sea spray aerosol concentrations from the FLEXPART model using the parameterisation presented in this study can be compared with the database of observed sea spray aerosol concentrations compiled by Grythe et al. (2014). This consists of observational data obtained at 21 monitoring sites and on-board ships during 11 research cruises (see Table 1 in Grythe et al., 2014) and totals over 20000 observations distributed over the global oceans. Figure 6 compares FLEXPART modelled with measured $\mathrm{Na}^{+}$concentrations using the sea spray source function presented here for four stations included in the comparison, Barrow, Malin Head, Valentia, and Zeppelin. When comparing measured and modelled concentrations at these four stations $R^{2}=0.62$, which compares favourably with those of other common parameterisations when the same comparison was conducted by Grythe et al. (2014) of between 0.18 and 0.66. However, the performance of the model using the source function presented here ranged considerably across the four stations - lower skill was observed at the two polar stations, Barrow, Alaska, and Zeppelin, Svalbard, which are characterised by lower concentrations of $\mathrm{Na}^{+}$overall. Their distance from large open seawater sources relative to Malin Head and Valentia, as well as the higher elevation of Zeppelin $(475 \mathrm{~m}$ above sea level), may mean that they are less representative of fresh sea spray aerosol. When comparing the entire data set $R^{2}=$ 0.16 , whilst it is $0.09,0.64$, and 0.09 when comparing only $\mathrm{PM}_{10}$ measurements, European Monitoring and Evaluation Programme (EMEP) station observations, and weekly observations, respectively. The value for the entire data set compares favourably with the correlations between modelled and observed sea spray aerosol concentrations for other common sea spray aerosol parameterisations found by Grythe et al. (2014). Here $R^{2}$ ranged between 0.03 and 0.17 when comparing the entire data set.

It is clear from Fig. 6 that the model is biased $\sim 50 \%$ low compared to the measurements. A low bias of similar magnitude was observed for many commonly deployed source functions tested by Grythe et al. (2014). It may be caused by the proximity of the observations to coastal wave breaking in the form of surf, which is not accounted for in the

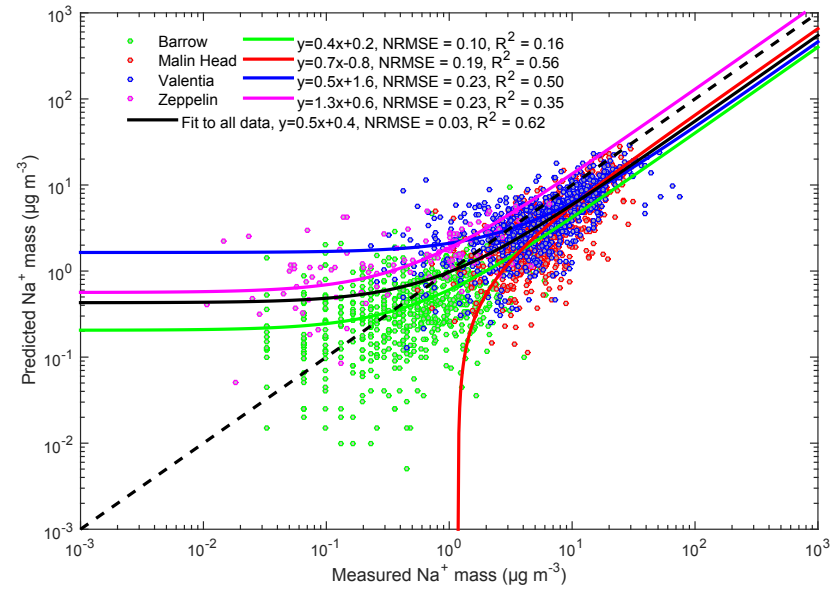

Figure 6. Comparison of FLEXPART modelled with measured $\mathrm{Na}^{+}$concentrations using the sea spray source function presented here for four stations included in the comparison by Grythe et al. (2014). Linear orthogonal fits are shown along with the correlation coefficient for the whole data set as well the individual stations. Compared to standard linear least-squares regression, which minimises the error only in the $y$ direction, the orthogonal fitting procedure used minimises the error in both the $x$ and $y$ directions. Also presented are the normalised root mean square errors (NRMSE) for the whole data set as well as the individual stations. Here the NRMSE is the root mean square error normalised to the difference between the maximum and minimum measured values for the entire data set or individual stations.

models, as well as inadequate treatment of sea spray aerosol post-production in the model. For example, errors in the rate of below cloud aerosol scavenging in the model will have knock-on effects on the aerosol residence time and how much of the aerosol produced by wave breaking was predicted to reach the point of measurement. Overall, given the uncertainty in the source function and the multitude of processes that must be accounted for in the model such as dry deposition and cloud processing, it is difficult to attribute too much to this disagreement. 
Table 3. Description of the simulated sensitivity experiments conducted in NorESM. The simulated climate was identical in all experiments.

\begin{tabular}{|c|c|c|c|c|}
\hline Run & Sea surface temperature & Wind speed at $10 \mathrm{~m}$ & $\begin{array}{l}\text { SSA wind speed } \\
\text { dependency* }\end{array}$ & $\begin{array}{l}\text { Sea spray } \\
\text { parameterisation }\end{array}$ \\
\hline 1 & Varying (from climatology) & Varying (computed online) & $F_{\mathrm{ent}}=2 \times 10^{-8} U_{10}^{3.41}$ & This study \\
\hline 2 & Fixed at $15^{\circ} \mathrm{C}$ in all grid cells & Varying (computed online) & $F_{\text {ent }}=2 \times 10^{-8} U_{10}^{3.41}$ & This study \\
\hline 3 & Varying (from climatology) & Varying (computed online) & $W=3.84 \times 10^{-6} U_{10}^{3.41}$ & Kirkevåg et al. (2013) \\
\hline
\end{tabular}

* Here $W$ denotes the whitecap fraction.

\section{Global simulations using an Earth system model}

We ran a total of three 2-year NorESM simulations after 1 year of spin-up. The model was set up as atmosphere only and the atmosphere was coupled with the data ocean and sea ice model (from CCSM4). In addition, the CAM4-Oslo aerosol life-cycle module was run offline with respect to the atmospheric component so that the aerosol changes induced by changing sea spray aerosol emissions in CAM4Oslo had no effect on the meteorology in any of the simulations. We chose not to include these feedbacks in order to obtain a clearer causal relation between sea surface temperature and sea spray aerosol given that all of these runs had exactly the same meteorology. All simulations employ emissions of $\mathrm{SO}_{2}, \mathrm{SO}_{4}$, particulate organic matter, and black carbon from fossil-fuel and bio-fuel combustion and biomass burning, taken from the IPCC AR5 data sets as in Kirkevåg et al. (2013). The description of the runs and the sea spray parameterisation is presented in Table 3 .

The global sea spray aerosol mass emission predicted by the model using the sea spray source function presented in this study is $1.84 \pm 0.92 \mathrm{Pg} \mathrm{yr}^{-1}$ whilst the global sea spray aerosol number emission is $(2.1 \pm 1.1) \times$ $10^{5}$ particles $\mathrm{m}^{-2} \mathrm{~s}^{-1}$ based on the uncertainty in oceanic air entrainment presented by Long et al. (2011). That this uncertainty of $\sim 50 \%$ only includes the uncertainty in air entrainment suggests that the total uncertainty will be much higher given that we include assumptions that the size distribution is independent of wind speed and that oceanic air entrainment is also independent of water temperature.

The global sea spray aerosol mass emission predicted by NorESM is significantly lower than that predicted by the Lagrangian particle dispersion model FLEXPART. This may be because the different models have different assumptions for the sea spray size representation or due to differences in the wind fields and SSTs used by the different models. NorESM uses the three modes described in Table 2, whilst FLEXPART used four log-normal distributions with modal diameters of 1.3, 9.4, 13.6, and $17.8 \mu \mathrm{m}$ and corresponding geometric standard deviations of 1.350, 1.100, 1.075, 1.050, respectively, to approximate the source function (as well as all others in the comparison).

To determine the influence of including a dependence on sea surface temperature in the sea spray aerosol source func- tion relative to no dependence on sea surface temperature, we ran a simulation where the sea surface temperature was fixed at $15^{\circ} \mathrm{C}$ over the entire ocean (a value in the range of the annual mean sea surface temperature of the global oceans). Figure 7 plots the difference in sea spray aerosol number flux, mass flux and clear-sky aerosol optical depth at $550 \mathrm{~nm}$ between the run with variable sea surface temperatures and the run with sea surface temperatures fixed at $15^{\circ} \mathrm{C}$ (the variable sea surface temperature run minus the fixed sea surface temperature run). Although changes in sea spray aerosol number fluxes are small in absolute terms, there is a large relative increase at high latitudes in both the Southern Hemisphere and the Northern Hemisphere when a temperature dependence is included. There is no discernible difference at lower latitudes in both hemispheres. When a temperature dependence is included, sea spray aerosol mass fluxes are slightly higher throughout the entire Northern Hemisphere, whilst they are significantly lower at higher latitudes in the Southern Hemisphere. Clear-sky aerosol optical depth values (Fig. 7c) are also generally higher in the Northern Hemisphere, when a sea surface temperature dependence is included, especially around the tropics, which is consistent with the observations of Sofiev et al. (2011). Averaged globally over a year, including a dependence on sea surface temperature, the sea spray source function decreases sea spray aerosol mass fluxes by $\sim 7 \%$, increases sea spray aerosol number fluxes by $\sim 14 \%$, and increases clear-sky aerosol optical depth by $<0.1 \%$ relative to a fixed sea surface temperature of $15^{\circ} \mathrm{C}$.

Figure 8a compares sea spray aerosol number concentrations modelled by NorESM using both the previous sea spray source function and that presented in the current study. From this figure it is clear that changing the sea spray parameterisation decreases the sea spray aerosol number concentration in the model in the lowest atmospheric layer. Over the Southern Ocean the effect is particularly noticeable - there are significantly fewer sea spray aerosol particles in the lowest layers of the model atmosphere in the model run using the parameterisation developed during this study when compared to the Kirkevåg et al. (2013) parameterisation.

Further evaluation of the new parameterisations deployment within NorESM is facilitated through comparison of modelled clear-sky aerosol optical depth at $550 \mathrm{~nm}$ in Fig. 8b. Across all regions in the Northern Hemisphere there is no discernible difference between all three model runs due to 
Table 4. Comparison of global averages (median) of sea spray aerosol column burdens $\left(C_{\mathrm{SSA}}\right)$, all-sky sea spray aerosol optical depth, mass-specific extinctions (ME), and sea spray atmospheric residence times between the three NorESM model runs.

\begin{tabular}{lrrrr}
\hline Model run & $\begin{array}{r}C_{\text {SSA }} \\
\left(\mathrm{mg} \mathrm{m}^{-2}\right)\end{array}$ & $\begin{array}{r}\text { SSA optical depth } \\
(-)\end{array}$ & $\begin{array}{r}\text { SSA ME } \\
\left(\mathrm{m}^{2} \mathrm{~g}^{-1}\right)\end{array}$ & $\begin{array}{r}\text { SSA residence } \\
\text { time (h) }\end{array}$ \\
\hline $\begin{array}{l}\text { Current parameterisation } \\
\text { (climatology SSTs) }\end{array}$ & 7.44 & 0.0379 & 5.10 & 29.6 \\
$\begin{array}{l}\text { Current parameterisation } \\
\left.\text { (SSTs fixed at } 15^{\circ} \mathrm{C}\right)\end{array}$ & 7.42 & 0.0383 & 5.16 & 29.2 \\
Previous parameterisation & 9.74 & 0.0302 & 3.10 & 10.0 \\
\hline
\end{tabular}

(a)

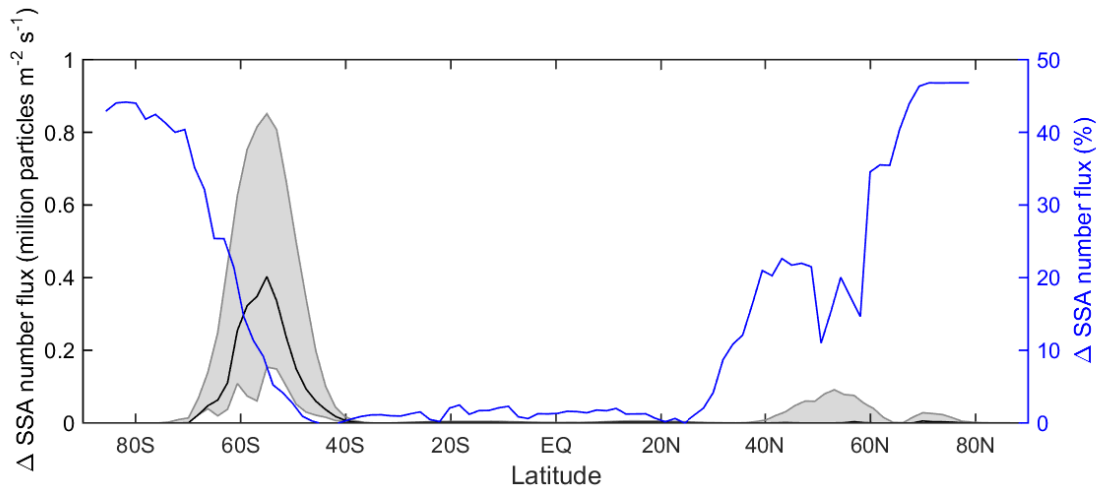

(b)

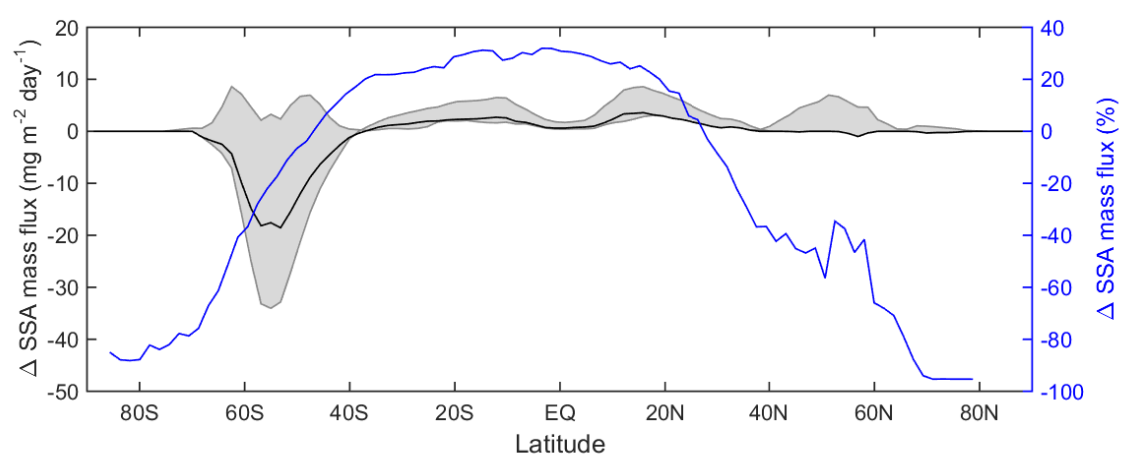

(c)

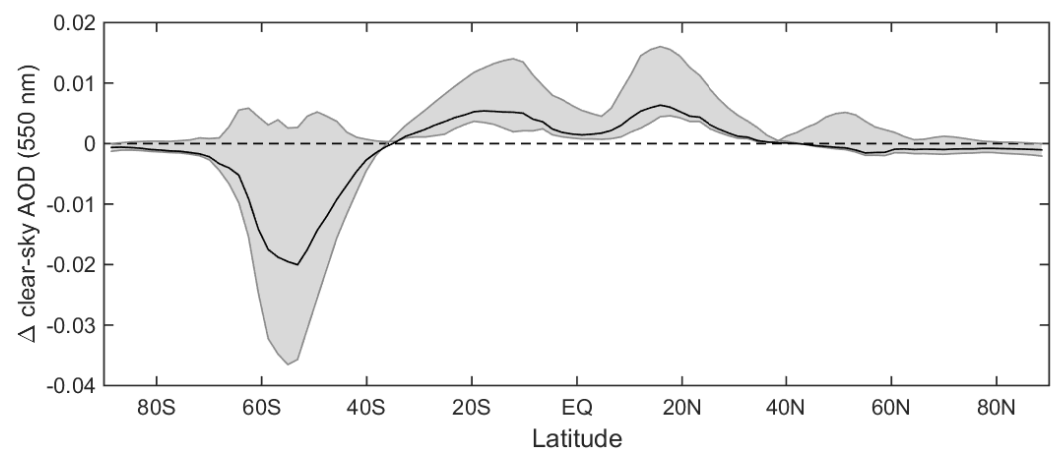

Figure 7. Zonal plots of the annually averaged (median) absolute difference in (a) SSA number fluxes, (b) SSA mass fluxes, and (c) clearsky aerosol optical depth at $550 \mathrm{~nm}$ between the parameterisation developed here with climatology sea surface temperatures and sea surface temperature fixed at $15^{\circ} \mathrm{C}$. Each plot was generated as the variable sea surface temperature simulation minus the fixed sea surface temperature simulation. Shaded areas represent 25th and 75th percentiles and the blue lines in (a) and (b) show percentage changes and refer to the right axes. 

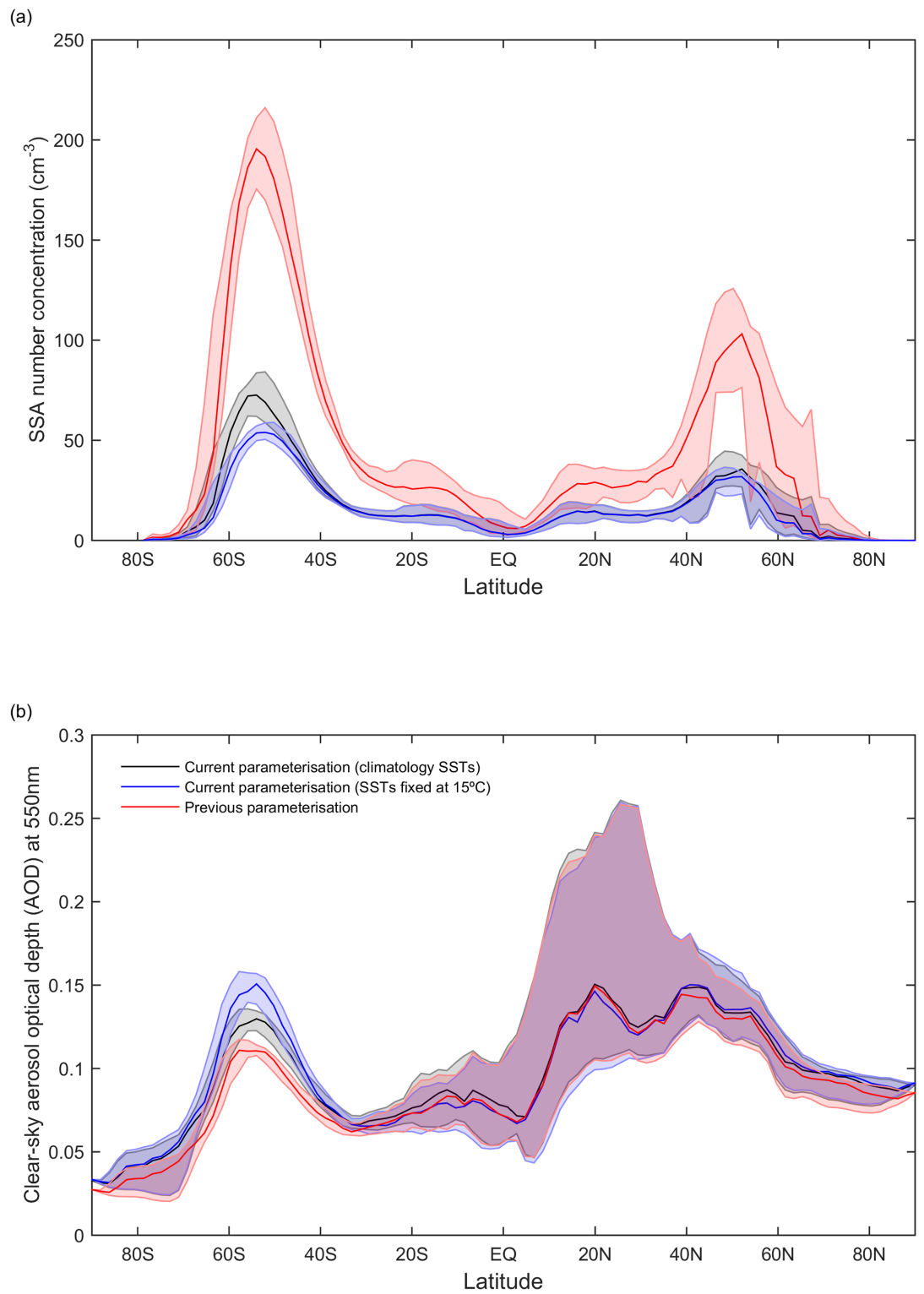

Figure 8. (a) Annually averaged (median) sea spray aerosol number concentration in the lowest model layer computed during the three NorESM runs. (b) Zonally and annually averaged clear-sky aerosol optical depth at $550 \mathrm{~nm}$ computed during the three NorESM runs (median). Shaded areas represent the 25 th and 75 th percentiles.

the dominance of aerosols other than sea spray aerosol. However, there are significant differences at higher latitudes in the Southern Hemisphere. Here, the model run using the sea spray aerosol parameterisation developed during this study and climatology sea surface temperatures simulates increased clear-sky aerosol optical depth.

It is also useful to consider the column burden of sea spray aerosol mass $\left(C_{\mathrm{SSA}}\right)$, the sea spray aerosol residence time, which is defined as the column (mass) burden divided by the loss (through wet and dry deposition), as well as the sea spray aerosol mass-specific extinction (ME), defined as the sea spray aerosol optical depth divided by the sea spray aerosol column (mass) burden. A comparison of these parameters between the previous parameterisation and that proposed in the current study is facilitated in Fig. 9 and Table 4. The column burdens of sea salt aerosol are generally lower in the parameterisation proposed in this study compared to the previous parameterisation of Kirkevåg et al. (2013), apart from in the polar regions. Globally averaged sea spray aerosol column burdens are 7.44 and $7.42 \mathrm{mg} \mathrm{m}^{-2}$ for the parameterisation with climatology sea surface temperatures and sea surface temperature fixed at $15^{\circ} \mathrm{C}$, respectively, compared to $9.74 \mathrm{mg} \mathrm{m}^{-2}$ with the previous parameterisation deployed in NorESM (Table 4). The parameterisation developed during 

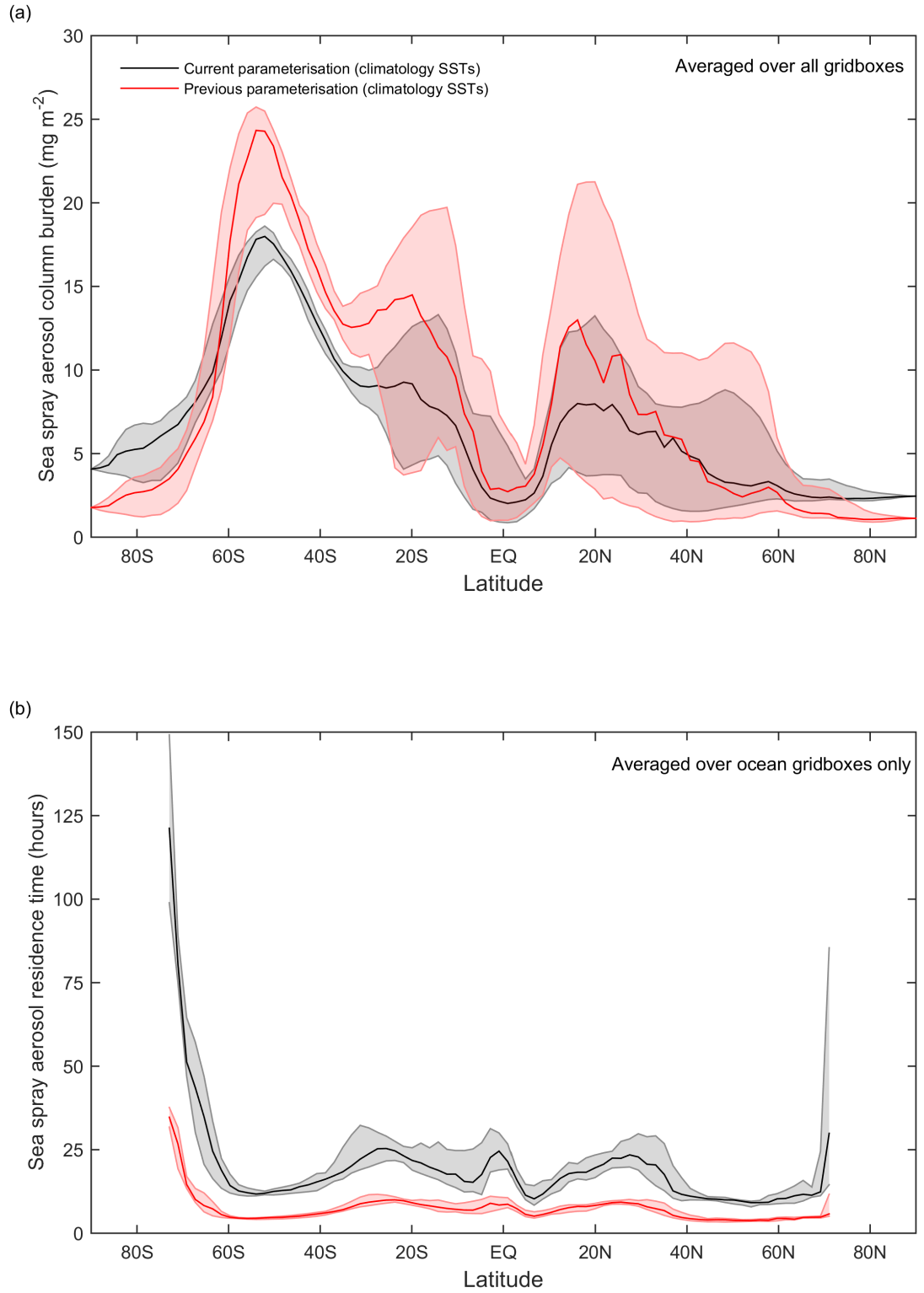

Figure 9. (a) Comparison of zonally (over all grid boxes) and annually averaged (median) sea spray aerosol column burden computed with the current parameterisation and the previous parameterisation (Kirkevåg et al., 2013). (b) Comparison of zonally (only ocean grid boxes) and annually averaged (median) sea spray aerosol residence time computed with the current parameterisation and the previous parameterisation (Kirkevåg et al., 2013). Shaded areas represent the 25th and 75th percentiles.

this study results in slightly increased numbers of accumulation mode particles across all latitudes but decreased amounts of particles with dry diameters greater than $1 \mu \mathrm{m}$ that dominate the mass production - hence the decreased column burden. Our calculated sea spray aerosol column burdens fall within the range of values reported by Textor et al. (2006), which has a mean of $15.5 \mathrm{mg} \mathrm{m}^{-2}$ (median of $12.7 \mathrm{mg} \mathrm{m}^{-2}$ ) and an inter-model diversity of $69 \%$.

The current parameterisation results in significantly longer sea spray aerosol residence times than the previous parameterisation, which is to be expected given that the effective radii of the sea spray aerosol are closer to the accumulation mode in the current parameterisation. The global mean residence time of $29.6 \mathrm{~h}$ for the current parameterisation and $10 \mathrm{~h}$ for the previous parameterisation can be compared with the AeroCom model comparison study (Textor et al., 2006), where the model mean residence time for sea spray aerosol was modelled as $12 \mathrm{~h}$ (median of $7.2 \mathrm{~h}$ ) with an inter-model diversity of $59 \%$. The sea spray aerosol residence time resulting from the new parameterisation is therefore outside the AeroCom model diversity interval. 
The current parameterisation results in significantly larger sea spray aerosol mass-specific extinction than the previous parameterisation. Kinne et al. (2006) reported sea spray aerosol mass-specific extinction for the AeroCom models. These values vary between 0.88 and $7.5 \mathrm{~m}^{2} \mathrm{~g}^{-1}$ (median $3 \mathrm{~m}^{2} \mathrm{~g}^{-1}$ ) for mass-specific extinction. Therefore, our calculated sea salt aerosol mass-specific extinction of $5.1 \mathrm{~m}^{2} \mathrm{~g}^{-1}$ falls within the inter-model diversities of AeroCom.

Kinne et al. (2006) also reported sea spray aerosol optical depth for the AeroCom models. These values vary between 0.003 and 0.067 (median 0.030). Compared with Kinne et al. (2006), our calculated sea salt aerosol optical depth of 0.038 falls within the inter-model diversities of AeroCom.

In essence, the changes to the modal diameters compensate for the coincident changes to the magnitudes of the fluxes of each mode, resulting in decreased sea spray aerosol number, increased residence time, and increased clear-sky aerosol optical depth compared to the previous parameterisation deployed in the model. When viewed as a whole these changes to the sea spray aerosol parameterisation may have important implications for aerosol optical properties and number concentrations, subsequently also affecting the indirect radiative forcing by (non-sea spray) anthropogenic aerosols (e.g. Hoose et al., 2009), especially at the regional level.

\section{Conclusions}

We have developed a parameterisation for inorganic sea spray aerosol production based upon state-of-the-art measurements of aerosol production using a temperaturecontrolled laboratory sea spray aerosol chamber. Using measurements of particle production in the size range 0.01 to $10 \mu \mathrm{m}$ dry diameter, we observed that particle production decreased non-linearly with increasing seawater temperature (between -1 and $30^{\circ} \mathrm{C}$ ) similar to previous findings. In addition, we observed that the particle effective radius, as well as the particle surface, particle volume and particle mass, increased with increasing water temperature due to increased production of particles with dry diameters greater than $1 \mu \mathrm{m}$. These observations might explain the contradiction between observations made using laboratory systems that attempt to replicate oceanic whitecaps, where decreasing particle production with increasing seawater temperature is observed, and observations of sea salt concentrations made in the field or inferred from aerosol optical depth measurements, which tend to increase with increasing seawater temperature. They also underline the need to model sea spray emissions separately for particles with dry diameters smaller and larger than $1 \mu \mathrm{m}$ when a dependence upon SST is included.

We have combined our measurements of particle production with measurements of the volume of air entrained by the plunging jet in order to determine the size-resolved particle flux as a function of air entrainment. By scaling in this way we avoid some of the difficulties associated with defining the "white area" of the laboratory whitecap - a contentious issue when using the more frequently applied whitecap method.

The here-derived inorganic sea spray source function was implemented in a Lagrangian particle dispersion model. An estimated annual global flux of inorganic sea spray aerosol of $5.9 \pm 0.2 \mathrm{Pg} \mathrm{yr}^{-1}$ was derived that is close to the median of estimates from the same model using a wide range of existing sea spray source functions. When using the source function derived here, the model also showed good skill in predicting measurements of $\mathrm{Na}^{+}$concentration at a number of field sites further underlining the validity of our source function.

In a final step, the sensitivity of a large-scale model to our new source function was tested by implementing it in NorESM. Compared to the previously implemented parameterisation, a clear decrease of sea spray aerosol number flux and increase in aerosol residence time was observed, especially over the Southern Ocean. At the same time an increase in aerosol optical depth due to an increase in the number of particles with optically relevant sizes was found. That there were noticeable regional differences may have important implications for aerosol optical properties and number concentrations, subsequently also affecting the indirect radiative forcing by non-sea spray anthropogenic aerosols.

\section{The Supplement related to this article is available online at doi:10.5194/acp-15-11047-2015-supplement.}

Acknowledgements. Matt Salter and Douglas Nilsson were supported by the Swedish Research Council (Vetenskapsrådet) and the Nordic Center of Excellence on Cryosphere-Atmosphere ( $\mathrm{NCoE}$ CRAICC). Paul Zieger was supported by a postdoc fellowship of the Swiss National Science Foundation (grant no. P300P2_147776). Alf Kirkevåg was supported by the Norwegian Research Council through the project EVA (grant no. 229771) and the NOTUR (nn2345k) and NordStore projects (ns2345k) as well as the NCoEs CRAICC and ESTICC and the EU FRP7 projects PEGASOS and ACCESS. The data from this study are available from the authors upon request.

Edited by: M. Boy

\section{References}

Abo Riziq, A., Erlick, C., Dinar, E., and Rudich, Y.: Optical properties of absorbing and non-absorbing aerosols retrieved by cavity ring down (CRD) spectroscopy, Atmos. Chem. Phys., 7, 15231536, doi:10.5194/acp-7-1523-2007, 2007.

Bentsen, M., Bethke, I., Debernard, J. B., Iversen, T., Kirkevåg, A., Seland, Ø., Drange, H., Roelandt, C., Seierstad, I. A., Hoose, C., and Kristjánsson, J. E.: The Norwegian Earth System Model, NorESM1-M - Part 1: Description and basic evalu- 
ation of the physical climate, Geosci. Model Dev., 6, 687-720, doi:10.5194/gmd-6-687-2013, 2013.

Bowyer, P. A., Woolf, D. K., and Monahan, E. C.: Temperature dependence of the charge and aerosol production associated with a breaking wave in a whitecap simulation tank, J. Geophys. Res., 95, 5313-5319, doi:10.1029/JC095iC04p05313, 1990.

Callaghan, A.: An improved whitecap timescale for sea spray aerosol production flux modeling using the discrete whitecap method, J. Geophys. Res., 118, 9997-10010. doi:10.1002/jgrd.50768, 2013.

Ceburnis, D., Rinaldi, M., Keane-Brennan, J., Ovadnevaite, J., Martucci, G., Giulianelli, L., and O'Dowd, C. D.: Marine submicron aerosol sources, sinks and chemical fluxes, Atmos. Chem. Phys. Discuss., 14, 23847-23889, doi:10.5194/acpd-14-238472014, 2014.

Clarke, A. D., Owens, S. R., and Zhou, J. C.: An ultrafine sea-salt flux from breaking waves: Implications for cloud condensation nuclei in the remote marine atmosphere, J. Geophys. Res., 111, D06202, doi:10.1029/2005JD006565, 2006.

Dahneke, B.: Slip correction factors for nonspherical bodies. II. Free molecule regime, Aerosol Sci., 4, 147-161, doi:, 1973.

de Leeuw, G., Andreas, E. L., Anguelova, M. D., Fairall, C. W., Lewis, E. R., O'Dowd, C. D., Schulz, M., and Schwartz, S. E.: Production flux of sea spray aerosol, Rev. Geophys., 49, RG2001, doi:10.1029/2010RG000349, 2011.

Gent, P. R., Danabasoglu, G., Donner, L. J., Holland, M. M., Hunke, E. C., Jayne, S. R., Lawrence, D. M., Neale, R. B., Rasch, P. J., Vertenstein, M., Worley, P. H., Yang, Z., and Zhang, M.: The community climate system model version 4, J. Climate, 24, 4973-4991, doi:10.1175/2011JCLI4083.1, 2011.

Gong, S. L.: A parameterization of sea-salt aerosol source function for sub- and super-micron particles, Global Biogeochem. Cy., 17, 1097, doi:10.1029/2003GB002079, 2003.

Grythe, H., Ström, J., Krejci, R., Quinn, P., and Stohl, A.: A review of sea-spray aerosol source functions using a large global set of sea salt aerosol concentration measurements, Atmos. Chem. Phys., 14, 1277-1297, doi:10.5194/acp-14-1277-2014, 2014.

Hinds, W.: Aerosol Technology: Properties, Behavior, and Measurement of Airborne Particles, John Wiley \& Sons, New York, 1999.

Hoose, C., Kristjansson, J. E., Iversen, T., Kirkevåg, A., Seland, Ø., and Gettelman, A.: Constraining cloud droplet number concentration in GCMs suppresses the aerosol indirect effect, Geophys. Res. Lett., 36, L12807, doi:10.1029/2009GL038568, 2009.

Iversen, T., Bentsen, M., Bethke, I., Debernard, J. B., Kirkevåg, A., Seland, Ø., Drange, H., Kristjansson, J. E., Medhaug, I., Sand, M., and Seierstad, I. A.: The Norwegian Earth System Model, NorESM1-M - Part 2: Climate response and scenario projections, Geosci. Model Dev., 6, 389-415, doi:10.5194/gmd-6-3892013, 2013.

Jaeglé, L., Quinn, P. K., Bates, T. S., Alexander, B., and Lin, J.-T.: Global distribution of sea salt aerosols: new constraints from in situ and remote sensing observations, Atmos. Chem. Phys., 11, 3137-3157, doi:10.5194/acp-11-3137-2011, 2011.

Kinne, S., Schulz, M., Textor, C., Guibert, S., Balkanski, Y., Bauer, S. E., Berntsen, T., Berglen, T. F., Boucher, O., Chin, M., Collins, W., Dentener, F., Diehl, T., Easter, R., Feichter, J., Fillmore, D., Ghan, S., Ginoux, P., Gong, S., Grini, A., Hendricks, J., Herzog, M., Horowitz, L., Isaksen, I., Iversen, T., Kirkevåg, A., Kloster,
S., Koch, D., Kristjansson, J. E., Krol, M., Lauer, A., Lamarque, J. F., Lesins, G., Liu, X., Lohmann, U., Montanaro, V., Myhre, G., Penner, J., Pitari, G., Reddy, S., Seland, O., Stier, P., Takemura, T., and Tie, X.: An AeroCom initial assessment - optical properties in aerosol component modules of global models, Atmos. Chem. Phys., 6, 1815-1834, doi:10.5194/acp-6-1815-2006, 2006.

Kirkevåg, A., Iversen, T., Seland, Ø., Hoose, C., Kristjánsson, J. E., Struthers, H., Ekman, A. M. L., Ghan, S., Griesfeller, J., Nilsson, E. D., and Schulz, M.: Aerosol-climate interactions in the Norwegian Earth System Model - NorESM1-M, Geosci. Model Dev., 6, 207-244, doi:10.5194/gmd-6-207-2013, 2013.

Lewis, E. R. and Schwartz, S. E.: Sea Salt Aerosol Production: Mechanisms, Methods, Measurements and Models - a Critical Review, Geophys. Monogr., Vol. 152, Amer. Geophys. Union, 2004.

Long, M. S., Keene, W. C., Kieber, D. J., Erickson, D. J., and Maring, H.: A sea-state based source function for size- and composition-resolved marine aerosol production, Atmos. Chem. Phys., 11, 1203-1216, doi:10.5194/acp-11-1203-2011, 2011.

Mårtensson, E. M., Nilsson, E. D., de Leeuw, G., Cohen, L. H., and Hansson, H. C.: Laboratory simulations and parameterization of the primary marine aerosol production, J. Geophys. Res., 108, 4297, doi:10.1029/2002JD002263, 2003.

Monahan, E. C. and O'Muircheartaigh, I.: Optimal power-law description of oceanic whitecap coverage dependence on wind speed, J. Phys. Oceanogr., 10, 2094-2099, doi:10.1175/15200485(1980)010<2094:OPLDOO>2.0.CO;2, 1980.

Monahan, E. C., Spiel, D. E., and Davidson, K. L.: Oceanic Whitecaps, in: A Model of Marine Aerosol Generation Via Whitecaps and Wave Disruption, 167-174, D. Reidel Publishing Company, 1986.

Mullins, B. J., Kampa, D., and Kasper, G.: Comment on "Performance evaluation of 3 optical particle counters with an efficient multimodal calibration method" (Heim et al., 2008) Performance of improved counter, J. Aerosol Sci., 49, 48-50, doi:10.1016/j.jaerosci.2012.01.009, 2012.

Najjar, R. G. and Keeling, R. F.: Analysis of the mean annual cycle of the dissolved oxygen anomaly in the World Ocean, J. Marine Res., 55, 117-151, doi:10.1357/0022240973224481, 1997.

Rosati, B., Wehrle, G., Gysel, M., Zieger, P., Baltensperger, U., and Weingartner, E.: The white-light humidified optical particle spectrometer (WHOPS) - a novel airborne system to characterize aerosol hygroscopicity, Atmos. Meas. Tech., 8, 921-939, doi:10.5194/amt-8-921-2015, 2015.

Salisbury, D. J., Anguelova, M. D., and Brooks, I. M.: On the variability of whitecap fraction using satellite-based observations, J. Geophys. Res., 118, 6201-6222, doi:10.1002/2013JC008797, 2013.

Salisbury, D. J., Anguelova, M. D., and Brooks, I. M.: Global distribution and seasonal dependence of satellitebased whitecap fraction, Geophys. Res. Lett., 41, 1616-1623, doi:10.1002/2014GL059246, 2014.

Salter, M. E., Nilsson, E. D., Butcher, A., and Bilde, M.: On the seawater temperature dependence of continuous plunging jet derived sea spray aerosol, J. Geophys. Res., 119, 9052-9072, doi:10.1002/2013JD021376, 2014.

Sofiev, M., Soares, J., Prank, M., de Leeuw, G., and Kukkonen, J.: A regional-to-global model of emission and transport of sea 
salt particles in the atmosphere, J. Geophys. Res., 116, D21302, doi:10.1029/2010JD014713, 2011.

Stocker, T. F., Qin, D., Plattner, G. K., Tignor, M., Allen, S. K., Boschung, J., Nauels, A., Xia, Y., Bex, V., and Midgley, P. M.: Climate Change 2013: The Physical Science Basis. Contribution of Working Group I to the Fifth Assessment Report of the Intergovernmental Panel on Climate Change, Cambridge Univ. Press, Cambridge, UK and New York, USA, 2013.

Stohl, A., Forster, C., Frank, A., Seibert, P., and Wotawa, G.: Technical note: The Lagrangian particle dispersion model FLEXPART version 6.2, Atmos. Chem. Phys., 5, 2461-2474, doi:10.5194/acp-5-2461-2005, 2005.

Stramska, M., Marks, R., and Monahan, E. C.: Bubble-mediated aerosol production as a consequence of wave breaking in supersaturated (hyperoxic) seawater, J. Geophys. Res., 95, 1828118288, doi:10.1029/JC095iC10p18281, 1990.

Struthers, H., Ekman, A. M. L., Glantz, P., Iversen, T., Kirkevåg, A., Seland, Ø., Martensson, E. M., Noone, K., and Nilsson, E. D.: Climate-induced changes in sea salt aerosol number emissions: 1870 to 2100, J. Geophys. Res., 118, 670-682, doi:10.1002/jgrd.50129, 2013.
Textor, C., Schulz, M., Guibert, S., Kinne, S., Balkanski, Y., Bauer, S., Berntsen, T., Berglen, T., Boucher, O., Chin, M., Dentener, F., Diehl, T., Easter, R., Feichter, H., Fillmore, D., Ghan, S., Ginoux, P., Gong, S., Grini, A., Hendricks, J., Horowitz, L., Huang, P., Isaksen, I., Iversen, I., Kloster, S., Koch, D., Kirkevåg, A., Kristjansson, J. E., Krol, M., Lauer, A., Lamarque, J. F., Liu, X., Montanaro, V., Myhre, G., Penner, J., Pitari, G., Reddy, S., Seland, Ø., Stier, P., Takemura, T., and Tie, X.: Analysis and quantification of the diversities of aerosol life cycles within AeroCom, Atmos. Chem. Phys., 6, 1777-1813, doi:10.5194/acp-6-1777-2006, 2006.

Wang, Z., King, S. M., Freney, E., Rosenoern, T., Smith, M. L., Chen, Q., Kuwata, M., Lewis, E. R., Pöschl, U., Wang, W., Buseck, P. R., and Martin, S. T.: The dynamic shape factor of sodium chloride nanoparticles as regulated by drying rate, Aerosol Sci. Tech., 44, 939-953, doi:10.1080/02786826.2010.503204, 2010.

Zábori, J., Krejci, R., Ström, J., Vaattovaara, P., Ekman, A. M. L., Salter, M. E., Mårtensson, E. M., and Nilsson, E. D.: Comparison between summertime and wintertime Arctic Ocean primary marine aerosol properties, Atmos. Chem. Phys., 13, 4783-4799, doi:10.5194/acp-13-4783-2013, 2013. 